\title{
Canopy level emissions of 2-methyl-3-buten-2-ol, monoterpenes, and sesquiterpenes from an experimental Pinus taeda plantation
}

Christopher D. Geron (United States Environmental Protection Agency, National Risk Management Research Laboratory, Research Triangle Park, NC, USA 27711 Corresponding author: Geron.chris@epa.gov)

Robert R. Arnts (United States Environmental Protection Agency, National Exposure Research Laboratory, Research Triangle Park, NC, USA 27711, now retired)

Ryan W. Daly (United States Environmental Protection Agency, National Risk Management Research Laboratory, Research Triangle Park, NC, USA 27711 Daly.ryan@epa.gov)

Alex B. Guenther (University of California, Irvine, CA, USA 92697-3100

Alex.Guenther@uci.edu)

Fred. L. Mowry (Nicholas School of the Environment and Earth Sciences, Duke University, Durham, NC, USA 27708, now retired)

\begin{abstract}
Emissions of biogenic volatile organic compounds (BVOCs) observed during 2007 from an experimental Pinus taeda plantation in Central North Carolina are compared with model estimates from the Model of Emissions of Gases and Aerosols from Nature (MEGAN) Version 2.1. Relaxed Eddy Accumulation (REA) estimates of 2-methyl-3-buten-2-ol (MBO) fluxes are a factor of 3-4 higher than MEGAN estimates. MEGAN monoterpene emission estimates were a factor of approximately two higher than REA flux measurements. MEGAN $\beta$-caryophyllene emission estimates were within $60 \%$ of growing season REA flux estimates but were several times higher than REA fluxes during cooler, dormant season periods. The sum of other sesquiterpene emissions estimated by MEGAN was several times higher than REA estimates throughout the year. Model components are examined to understand these discrepancies. Measured summertime leaf area index (LAI) (and therefore foliar biomass) is a factor of two higher than assumed in MEGAN for the Pinus taeda default. Increasing the canopy mean MBO emission factor from 0.35 to $1.0 \mathrm{mg} \mathrm{m}^{-2} \mathrm{hr}^{-1}$ also reduces MEGAN vs. REA flux differences. This increase is within current $\mathrm{MBO}$ emission factor uncertainties. The algorithm within MEGAN which adjusts isoprene emission estimates as a function of the temperature and light of the previous 24 hours seems also to improve the seasonal MEGAN MBO correlation with REA fluxes. Including the effects of the previous 240 hours, however, seems to degrade temporal model correlation with fluxes. Monoterpene and sesquiterpene composition data from the REA are compared with MEGAN2.1 estimates and also branch enclosure and needle extract data collected at this site. To our knowledge, the flux data presented here are the first reported for MBO and sesquiterpenes from a Pinus taeda ecosystem.
\end{abstract}

Keywords: Pinus taeda, methyl butenol, monoterpenes, sesquiterpenes, Biogenic Volatile Organic Compound, Model of Emissions of Gases and Aerosols from Nature (MEGAN)

\subsection{Introduction}

The southeastern U.S. (Alabama, Arkansas, Florida, Georgia, Louisiana, Kentucky, Mississippi, North Carolina, eastern Oklahoma, South Carolina, Tennessee, eastern Texas, and Virginia) produces approximately 60 percent of the nation's timber products. This region produces more 
timber than any other single country in the world and is projected to remain the dominant producing region for many decades to come (Prestemon and Abt, 2008). Nearly all of this production is from privately held forest land. Timber prices are projected to increase in the United States over the next 40 years and are expected to incent forestland owners to invest heavily in timber-growing technology and intensive forest management. Timberland area is projected to increase in many parts of the South, especially in western and northern portions (Alabama, Arkansas, Kentucky, Tennessee, and Virginia) due to agricultural land conversion to forests, primarily pine tree plantations. The area of pine plantations is expected to increase by 67 percent (from 33 to 54 million acres) between 1995 and 2040, as non-plantation timberland is projected to decrease regionally by $15 \%$. Both current and projected plantation area is dominated by Pinus taeda (>80\% currently), with much of the balance planted in slash pine (Pinus elliottii) on the southern coastal plain (Fox et al., 2006). Pinus taeda is also the single most economically important species in the global wood products economy, accounting for $16 \%$ of the world's annual timber supply (Neale and Wheeler, 2004). Over $80 \%$ of new plantations are established with genetically improved Pinus taeda seedlings (McKeand et al, 2003), produced via controlled pollination, cloning, and tissue culture, with the goals of improving biomass production, stem/fiber quality, crown characteristics, and disease resistance. Since the southeastern U.S. has persistent $\mathrm{PM}_{2.5}$ and $\mathrm{O}_{3}$ air quality problems that are complicated by BVOC emissions (Carlton et al., 2009; Trainer et al., 1987), it is important to improve understanding of BVOC fluxes from Pinus taeda, characterize BVOC emission model performance, and examine effects such as genetic and regional variability on BVOC emissions.

The importance of isoprene and monoterpenes in atmospheric chemistry and air quality analyses has been well documented (Trainer et al., 1987). Based on published sesquiterpene aerosol yields and branch enclosure measurements from Pinus taeda, Helmig et al. (2006) determined that sesquiterpenes can significantly impact secondary organic aerosol (SOA) concentrations in the southeastern U.S. Carleton et al. (2009) conclude that "Global biogenic emissions of isoprene $\left(600 \mathrm{Tg} \mathrm{yr}^{-1}\right)$ are sufficiently large that the formation of SOA in even small yields results in substantial production of atmospheric particulate matter, likely having implications for air quality and climate". The compound 2-methyl-3-buten-2-ol (MBO) has also been found to contribute to the chemistry of SOA and tropospheric ozone in the western United States (Jaoui et al., 2011; Steiner et al., 2007). Emissions of MBO from several western Pinus species (e.g. P. contorta, $P$. jeffreyii, and $P$. ponderosa) are comparable to isoprene emissions from Quercus and Populus species (Harley et al., 1998), while eastern U.S. Pinus species have considerably lower emission capacities. MBO flux studies have been conducted over western U.S. coniferous forests (Baker et al., 1999, 2001; Schade et al., 2000; Schade and Goldstein 2001; Kaser et al., 2013b), but to date, no $\mathrm{MBO}$ or sesquiterpene flux data have been documented from eastern forests. Here we report BVOC fluxes from loblolly pine (Pinus taeda) with a primary focus on MBO. We discuss monoterpene and sesquiterpene emissions as well, but discuss these in more detail in Daly and Geron (in preparation). Hourly BVOC emission outputs from the Model of Emissions of Gases and Aerosols from Nature (MEGAN) Version 2.1 (described in Section 2.2) are compared with our hourly REA flux measurements as a means of evaluating MEGAN2.1 performance for this Pinus taeda dominated ecosystem.

\subsection{Methods}

\subsection{Flux Measurement}

Biogenic Volatile Organic Compound (BVOC) flux data were collected at the Blackwood Division of Duke Forest $\mathrm{C}-\mathrm{H}_{2} \mathrm{O}$ Free Atmosphere Carbon Transfer Scheme (FACTS1) 
Research Site in Orange County, North Carolina $\left(35.98^{\circ} \mathrm{N}, 79.09^{\circ} \mathrm{W}\right)$ during 2007 . The site is described in more detail in Geron (2009). The REA system was deployed from the center walkup tower at Ring 6, which is a control (non- $\mathrm{CO}_{2}$ fumigated) forest plot within the plantation. The pine plantation within and near Ring 6 was assumed to be similar in genetic composition to the balance of the forest within the flux footprint of the REA system inlet.

We employed a form of relaxed eddy accumulation (REA) technology to measure the vertical flux (exchange) of volatile organic compounds emitted from an even age Loblolly pine plantation to the atmosphere. Arnts et al., (2013) notes that REA theory is derived from eddy correlation theory, where the vertical flux F, can be determined by the product of a constant, $\beta$, times the standard deviation of the vertical wind velocity $\sigma_{\mathrm{w}}$ (where the mean vertical wind velocity is zero), and the difference between the mean updraft concentration and the mean downdraft concentration $\left(C_{u p}-C_{d o w n}\right)$ :

$$
F=\beta \sigma_{w}\left(C_{u p}-C_{d o w n}\right)
$$

A detailed description of the REA used in this study is described in Arnts et al. (2013), and the following key features are taken from that paper. The REA demonstrated capabilities to measure important reactive biogenic, especially precursors of secondary organic aerosol, volatile organic fluxes including monoterpenes and sesquiterpenes, as well as their polar oxygenated species, at levels as low as $10 \mu \mathrm{g} \mathrm{C} \mathrm{m}^{-2} \mathrm{hr}^{-1}$ (15 liter sample size and detection by GC with flame ionization detection). The system demonstrated these capabilities over ambient temperatures ranging from $\sim 0^{\circ}$ to $35^{\circ} \mathrm{C}$. Key design features which facilitated this performance included: 1) integration of gas phase ozone removal to permit VOC collection without on-adsorbent losses, 2) a short inert inlet operated under turbulent flow to effect efficient transmission of sampled air to the segregator valves with minimal axial mixing (smearing), 3) mass flow control for all critical gas streams, 4) a heated sample path through the tubing, segregator valves, and reaction coils, 5) cooled accumulator tubes, 6) temperature control of mass flow controller module to stabilize flow control, 7) a two component internal standard which permitted correction of accumulator volume for flow switching transients and monitoring for valve failure and VOC adsorbent breakthrough and 8) a 12 tube magazine of high capacity adsorbent tubes with two sets of 6-port manifold valves to permit up to six consecutive flux measurements without operator attention.

Under conditions of horizontal surface winds passing over the experimental canopy, up and down drafts 5-10 meters above the canopy are collected in separate adsorbent tubes over a 55 minute integration period. Flux estimates are then corrected to equivalent hourly fluxes. Flux measurements were conducted between 8 AM and 6 PM. Nighttime measurements were not attempted since nocturnal atmospheric stability precludes use of the REA technique. Draft samples represent contributions of canopy emissions in inverse proportion to the upwind source distance. Horizontal fluctuations in wind vector also contribute to averaging of any inhomogeneity in canopy emission surfaces. Ozone removal was performed continuously using a gas phase scavenger (trans-2-butene) to minimize biogenic VOC losses within the REA (Arnts 2008).

After sampling, tubes are capped and returned to the laboratory for analysis. A custom built thermal desorption apparatus was constructed to process the non-standard large size tubes (Arnts, 2010). This system allowed up to 16 tubes to be thermally desorbed, cryogenically focused and injected into a 5890 Hewlett-Packard gas chromatograph with flame ionization for quantification and identification using a 5973-MSD (Agilent Technologies, Palo Alto, CA) and mass spectral matching with the NIST/EPA data base using. The sample path through the system was passivated with Restek's Sulfinert process and heated to prevent adsorptive losses. The 
processing of the tubes includes steps to remove residual water vapor and trans-2-butene before high temperature thermal desorption. Also, an n-alkane internal standard was added to aid in retention time adjustment and peak identification. The flame ionization detector was calibrated with a Scott prepared mixture of isooctane and 2,5-diemethylhexane in nitrogen which was regularly calibrated against a NIST-certified propane in nitrogen standard. Based on mass spectral analysis of field samples, pure samples of the tentatively identified compounds were obtained and used to prepare dilute mixtures in the laboratory. These mixtures were then sampled and analyzed to compare with the field samples. Retention time matches provided additional confidence in peak identification of field samples. For compounds for which no commercial sources were available, retention time indices were compared with published values in the NIST data base to help with identification.

The adsorbent collector tubes were sized to achieve targeted minimum detectable fluxes considering adsorbent retention- recovery characteristics of the biogenic analytes, detection limits of the chromatographic detectors, and optimum flux integration periods. The adsorbent tube collectors and analytical scheme were designed to measure compounds ranging in volatility from 2-methyl-3-buten-2-ol (MBO) thru mono and sesquiterpenes at total sample volumes of 55 liters (10 to 15 liters of draft sample and the balance in zero nitrogen) at $25{ }^{\circ} \mathrm{C}$. Most of the biogenic VOCs were retained on the first adsorbent bed (Tenax) with a second bed of Carbotrap to retain internal standards (alkanes). During the field measurement campaign we were unable to maintain adsorbent tube temperature at $25{ }^{\circ} \mathrm{C}$ under some very hot and humid conditions. Recognizing that these conditions might cause the most volatile VOC, MBO, to migrate out of the Tenax and onto the Carbotrap bed, resulting in dehydration of MBO to isoprene, we conducted laboratory tests to determine worst case losses. These experiments showed that a $5{ }^{\circ} \mathrm{C}$ elevation did not cause an accompanying significant increase loss of MBO but recoveries at 25 ${ }^{\circ} \mathrm{C}$ and $30{ }^{\circ} \mathrm{C}$ showed that about half of the MBO dehydrated to isoprene.

\subsection{Emission Model}

Fluxes of BVOC were compared with MEGAN version 2.1 (Guenther et al., 2006, 2012). MEGAN2.1 (referred to hereafter as MEGAN) is a commonly used modeling system to simulate landscape net emissions of $\mathrm{VOC}, \mathrm{CO}$, and $\mathrm{NO}$ from natural and agricultural landscapes. MEGAN is designed to be flexible with respect to user inputs. Landcover data and emission factor files may be input by the user, or default plant functional types and emission factor files specific to these functional types may be used. Here, a custom plant functional type (PFT) was used to represent a pine plantation based on the MEGAN parameters used for loblolly pine (Pinus taeda). The default canopy average MBO area-based emission factor is $350 \mathrm{\mu g} \mathrm{m}^{-2} \mathrm{~h}^{-1}$, which compares to $3500 \mu \mathrm{g} \mathrm{m}^{-2} \mathrm{~h}^{-1}$ for the Pinus ponderosa PFT. Canopy monoterpene emission factors (EFs) sum to $1650 \mu \mathrm{g} \mathrm{m}^{-2} \mathrm{~h}^{-1}$ at a leaf temperature of $303.3 \mathrm{~K}$. Slightly over half of this value $\left(840 \mu \mathrm{g} \mathrm{m}^{-2} \mathrm{~h}^{-1}\right)$ is $\alpha$-pinene. $\beta$-Pinene $\left(330 \mu \mathrm{g} \mathrm{m}^{-2} \mathrm{~h}^{-1}\right)$, limonene $\left(130 \mu \mathrm{g} \mathrm{m}^{-2} \mathrm{~h}^{-1}\right), \Delta 3$ carene $\left(100 \mu \mathrm{g} \mathrm{m}^{-2} \mathrm{~h}^{-1}\right), \beta$-myrcene $\left(80 \mu \mathrm{g} \mathrm{m}^{-2} \mathrm{~h}^{-1}\right)$, trans- $\beta$-ocimene $\left(60 \mu \mathrm{g} \mathrm{m}^{-2} \mathrm{~h}^{-1}\right)$, sabinene $(25$ $\left.\mu \mathrm{g} \mathrm{m}^{-2} \mathrm{~h}^{-1}\right)$, and the sum of other monoterpenes $\left(85 \mu \mathrm{g} \mathrm{m}^{-2} \mathrm{~h}^{-1}\right)$ compose the balance. The total sesquiterpene EF is $240 \mu \mathrm{g} \mathrm{m}^{-2} \mathrm{~h}^{-1}$ and is composed of $\beta$-caryophyllene $\left(50 \mu \mathrm{g} \mathrm{m}^{-2} \mathrm{~h}^{-1}\right), \alpha-$ farnesene $\left(40 \mu \mathrm{g} \mathrm{m}^{-2} \mathrm{~h}^{-1}\right)$, and the sum of other sesquiterpenes $\left(150 \mu \mathrm{g} \mathrm{m}^{-2} \mathrm{~h}^{-1}\right)$. These EFs increase proportionally to changes in leaf area index (LAI, defined as the vertically integrated projected [single-sided] leaf surface area per unit of ground area, in $\mathrm{m}^{2} \mathrm{~m}^{-2}$ ) for the non-lightdependent compounds. Light-dependent compounds are less affected by changes in LAI due to shading effects. The default LAI of 3 for loblolly pine was used.

We examine the influence of prior temperature and light (over the past 24 and 240 hours) on isoprene and MBO fluxes in MEGAN. Model inputs of solar radiation ( $\mathrm{W} \mathrm{m}^{-2}$ ), upper canopy air 
temperature $(\mathrm{K})$, humidity $\left(\mathrm{g} \mathrm{kg}^{-1}\right)$, and wind speed $\left(\mathrm{m} \mathrm{s}^{-1}\right)$ are hourly averages from the FACTS1 database (ftp://ftp.face.bnl.gov/FACTS1, accessed April 23, 2016). The FACTS1 site experienced no drought from January through April of 2007, moderate drought from mid-May through mid-August, and then drought of increasing intensity from late August (severe) through December (exceptional, http://droughtmonitor.unl.edu/MapsAndData/DataTables/PopulationStatisticsTable.aspx, last accessed January 15, 2015). MEGAN model outputs were chronologically synchronized with the 2007 BVOC REA flux estimates for comparison.

\subsection{Needle Essential Oil Extracts}

Loblolly pine (Pinus taeda) needles were harvested periodically from the same southern-exposed upper canopy branch at Ring 6 throughout the year. Needle samples were stored in plastic bags and kept in cold storage $\left(-20^{\circ} \mathrm{C}\right)$ until extraction. BVOC were partitioned from needle sample tissue by extraction with the non-polar solvent hexane. Tridecane was added to the solvent as an internal standard for aid in calibrations and chromatographic compound identification. The goal was to extract $\mathrm{C}_{10}-\mathrm{C}_{15}$ BVOC from foliage samples, while expanding the analyte target range to $\mathrm{C}_{5}-\mathrm{C}_{15}$ using cryogenic gas chromatography. The limit of detection $(L D)$ for individual BVOC is approximately 10 to $100 \mu \mathrm{g} \mathrm{C} \mathrm{g}$ (needle dry weight) ${ }^{-1}$ for $20-200 \mathrm{mg}$ (dry weight) foliage samples.

Needle extraction samples were analyzed using an Agilent 6890 Gas Chromatograph with a liquid injection autosampler and simultaneous Flame Ionization Detection (FID) / Mass Selective Detection (MSD Model 5975C, Agilent Technologies, Santa Clara, CA, USA 95051). A HP$5 \mathrm{MS}$ column (30m x $0.25 \mathrm{~mm} \times 0.25$ um film thickness) was used, and the carrier gas was He with a column head pressure of $22.7 \mathrm{psi}$, a constant flow rate of $2.5 \mathrm{ml} \mathrm{min}^{-1}$, and average velocity of $47 \mathrm{~cm} \mathrm{~s}^{-1}$. The oven temperature was held for 2 minutes at $40^{\circ} \mathrm{C}$, increased to $250^{\circ} \mathrm{C}$ at $6{ }^{\circ} \mathrm{C} \mathrm{min}{ }^{-1}$, and then held at $250^{\circ} \mathrm{C}$ for 2 min. Authentic BVOC and n-alkane $\left(\mathrm{C}_{8}-\mathrm{C}_{15}\right)$ standards were used for FID calibration and to verify MSD compound identification. Further details will be published separately by Daly and Geron (in preparation).

\subsection{Measurement and Emission Model Uncertainties}

Uncertainties associated with combined adsorbent tube BVOC collection/desorption and GC/FID analysis were examined in the laboratory by collecting 2-8 ppbC mixing ratios of $\mathrm{MBO}, \alpha$-pinene, $\mathrm{d}-$ limonene, and $\beta$-caryophyllene from a dynamic standard generation system (Arnts 2010) onto a subset of the REA sample tubes. These data are those used to test MBO recovery discussed in Section 2.1. Coefficients of variation (CV) ranged from 7-13\% under "worst case scenarios" described above. The analytical uncertainties in $\beta$-caryophyllene measurement were not significantly different from the other BVOC, however, within canopy loss of $\beta$-caryophyllene and other reactive BVOC (discussed in Section 3.0) would probably increase the overall uncertainty in fluxes of these reactive compounds. An estimate of the REA sample collection uncertainty of $\pm 5 \%$ can be inferred from the water vapor samples collected by the system (Arnts et al. 2013). Since the REA and analytical uncertainties are independent of each other, the total flux uncertainty is estimated to range from approximately $9-14 \%$.

Additional insight into REA flux uncertainty can be derived by comparing the BVOC fluxes calculated from the integrated flow through the updraft and downdraft channels with the BVOC fluxes calculated from channel volumes corrected by the internal standard mixing ratio (approximately $25 \mathrm{ppb} \mathrm{C}$ each of methylcyclohexane and 2-methylheptane, which also have an analytical uncertainties). The fluxes corrected with the internal standards were $5-11 \%$ higher than the uncorrected values, although the correction was somewhat greater $(\sim 17 \%)$ for 
wintertime $\beta$-caryophyllene. Sesquiterpene and oxygenated monoterpene concentrations were low and variable in the non-growing season measurements.

An assessment of the MEGAN model performance requires consideration of the expected model predictability. The uncertainty associated with biogenic emission model predictions is difficult to assign given the lack of suitable observations for characterizing biogenic emission models. Lamb et al. (1987) made the first attempt at quantifying the uncertainties associated with biogenic VOC emission estimates. They identified four major sources of uncertainty in these estimates: emission rate measurements, a single parameter emission algorithm, biomass density estimates, and land use (vegetation type) spatial distributions. They estimated a total uncertainty of $210 \%$ using a propagation of uncertainties associated with each of these four model components. Hanna et al. (2005) attempted a more thorough assessment of the uncertainties in biogenic emission model estimates by applying a Monte Carlo approach to characterize uncertainties in the BEIS3 model. They assigned an uncertainty to each variable in the model and categorized each variable as having either a lognormal or normal distribution. There were 10 variables used in BEIS3 to estimate isoprene emission and only 3 variables used to model monoterpenes and other VOC. They concluded that the $95 \%$ confidence range on the calculated uncertainty in isoprene emission was about one order of magnitude while the calculated uncertainty for monoterpenes and other VOC was only $\pm 20 \%$. This is in contrast with field studies that indicate that isoprene emissions, which have been relatively well studied, typically agree within about $30 \%$ of canopy scale observations while modeled and measured values for other VOC compounds, for which there are few or no observations from many ecosystem types, can differ by more than a factor of 10 (Guenther 2013). The uncertainties assigned to individual model components may not be appropriate for landscapes where there have been no measurements to parameterize the model. Rather than assign different uncertainties to isoprene and other compounds, it may be more meaningful to assign model uncertainties that range from $30 \%$ for a compound emitted at a site that has been characterized to a factor of 5 for a compound emitted from an ecosystem that has not been studied. Aircraft observations across large regions suggest that model predictions of compounds emitted from ecosystems that have been characterized in some way are within a factor of two of observations (Misztal et al. 2014, Warneke et al. 2010).

\subsection{Canopy Characteristics}

To facilitate comparisons between seasonal LAI and flux estimates, an LAI interpolation function was fitted to the observed monthly mean LAI measured in 2007 (reference the FACTS1 database cited previously) as a function of Day of Year (DOY). The non-linear fit yields:

$\mathrm{LAI}=\mathbf{2 . 9}+\left(\mathbf{2 . 8 7 1 5} \times(\mathbf{1}-\exp (-\mathbf{0 . 0 5 6 4} \times \mathrm{DOY}))^{\mathbf{1 9 1 . 4}}\right)$ for $\mathrm{DOY} \leq 280$, and
$\mathrm{LAI}=\mathbf{2 . 9}+(\mathbf{2 . 8 2 8 4} \times(\mathbf{3 6 5}-\mathrm{DOY}) / \mathbf{8 5}))$ for $\mathrm{DOY}>280$

where LAI is in $\mathrm{m}^{2}$ projected leaf area per $\mathrm{m}^{2}$ ground area, and DOY is day of year. These equations reproduce the observed sigmoidal increase in LAI during spring to the summertime maximum, followed by linear decline to $\sim 1 / 2$ full needle mass at year's end due to abscission of needles produced during the growing season of the previous calendar year. This non-linear pattern (Figure 1) simulates the seasonal dynamics documented by Vose et al. (1988) for LAI in Pinus taeda plantations.

The non-nitrogen fertilized Ring 6 quadrant had $570 \mathrm{~g} \mathrm{~m}^{-2}$ of pine litterfall in 2008, indicating a peak summer pine LAI of approximately 5 in 2007. Since about half of the summer peak needle mass in the summer of 2007 would have abscised in 2008, a leaf mass per unit projected area of $230 \mathrm{~g} \mathrm{~m}^{-2}$ is consistent with a peak pine LAI of approximately 5. Invading hardwoods 
(Liquidambar styraciflua, Liriodendron tulipifera, Acer rubrum, and Quercus species) contributed roughly an additional unit of LAI in the pine plantations, accounting for the peak LAI of $\sim 6$ as shown in Figure 1.

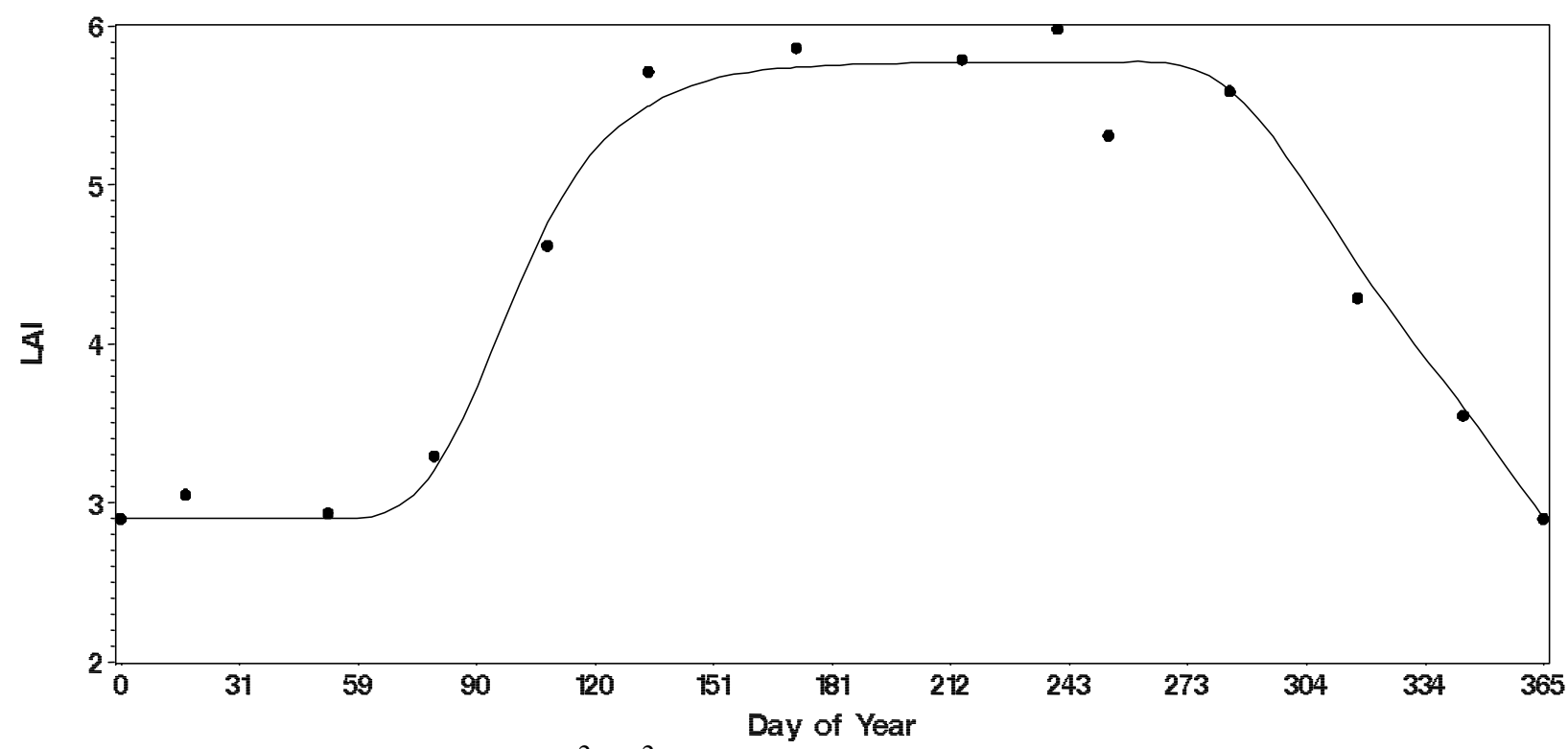

Figure 1. Observed mean LAI in $\mathrm{m}^{2} \mathrm{~m}^{-2}$ values from FACTS1 plots 1, 5, and 6 (non- $\mathrm{CO}_{2}$ fertilized control plots) in 2007 are shown as black solid dots. The solid line shows a fit of nonlinear and linear functions (Equations 2 and 3) used to describe the seasonal LAI pattern.

\subsection{Results and Discussion}

Table 1 compares the REA flux estimates with the MEGAN model outputs for the corresponding hourly flux measurement periods. MEGAN assigns "canopy escape efficiency" (CEE) values to individual BVOCs. CEE is the percentage of leaf emission of a given BVOC which escapes the canopy into the atmosphere above, and account for potential losses due to deposition and reactions with oxidants, primarily $\mathrm{O}_{3}, \mathrm{NO}_{3} \cdot$, and $\mathrm{OH} \bullet$. These values range from approximately $10 \%$ for very reactive compounds such as $\beta$-caryophyllene to over $90 \%$ for the pinenes, isoprene and MBO (Stroud et al., 2005; Guenther et al., 2012). Since the REA captures fluxes 5-10 meters above the mean canopy height (which varies somewhat with wind direction), it is appropriate to incorporate CEE into the model estimates for valid comparison with REA measurements. At the Pinus taeda site used for this study, Arnts et al. (2013) estimated CEE to be $\geq 93 \%$ for camphene, p-cymene, MBO, camphor, $\beta$-phellandrene, linalool, $\alpha$-pinene, $\beta$-pinene and within $80-87 \%$ for sabinene, nopinone, $\alpha$-copaene, terpin-4-ol, $\alpha$-terpineol and limonene. Very significant losses were estimated for $\alpha$-bergamotene $(\mathrm{CEE}=76 \%)$, myrcene $(\mathrm{CEE}=69 \%)$ and especially for $\beta$ caryophyllene, $\alpha$-phellandrene and $\alpha$-humulene $(\mathrm{CEE}=40 \%)$.

Table 1. Hourly REA flux measurements $\left(\mu \mathrm{g} \mathrm{C} \mathrm{m}{ }^{-2} \mathrm{~h}^{-1}\right.$ ) during 2007 compared with hourly MEGAN 2.1 outputs for the same times and meteorological conditions.

\begin{tabular}{|c|c|c|}
\hline \multicolumn{3}{|c|}{ Fall, Winter, and Early Spring } \\
\hline Compound & REA & MEGAN \\
\hline MBO & 76 & 30 \\
\hline$\alpha$-pinene & 250 & 290 \\
\hline Other MNT & 180 & 410 \\
\hline$\beta$-caryophyllene & 1.6 & 12 \\
\hline Other SQT & 1.9 & 46 \\
\hline
\end{tabular}

\begin{tabular}{|c|c|c|}
\hline \multicolumn{3}{|c|}{ Mid-Spring through Summer } \\
\hline Compound & REA & MEGAN \\
\hline MBO & 530 & 180 \\
\hline$\alpha$-pinene & 560 & 1040 \\
\hline Other MNT & 630 & 1320 \\
\hline$\beta$-caryophyllene & 41 & 65 \\
\hline Other SQT & 38 & 250 \\
\hline
\end{tabular}


We examined the possible effects of the late season drought on MEGAN versus REA flux patterns. No obvious drought effects could be detected. MEGAN somewhat under-predicted $\alpha$ pinene early in the growing season and then over-predicted during August (Figure 2). However, this pattern was not apparent in the other compounds. Nonetheless, drought effects should be examined in future studies by employing continuous flux measurement techniques.

Figure 2. Individual hourly REA flux measurements (black dots) in $\mathrm{mg} \mathrm{C} \mathrm{m}^{-2} \mathrm{~h}^{-1}$ for $\alpha$-pinene, sum of other monoterpenes, $\beta$-caryophyllene, sum of other sesquiterpenes, and MBO compared with hourly MEGAN 2.1 outputs (red vertical lines) over the course of 2007 at the FACTS1 site in North Carolina. 


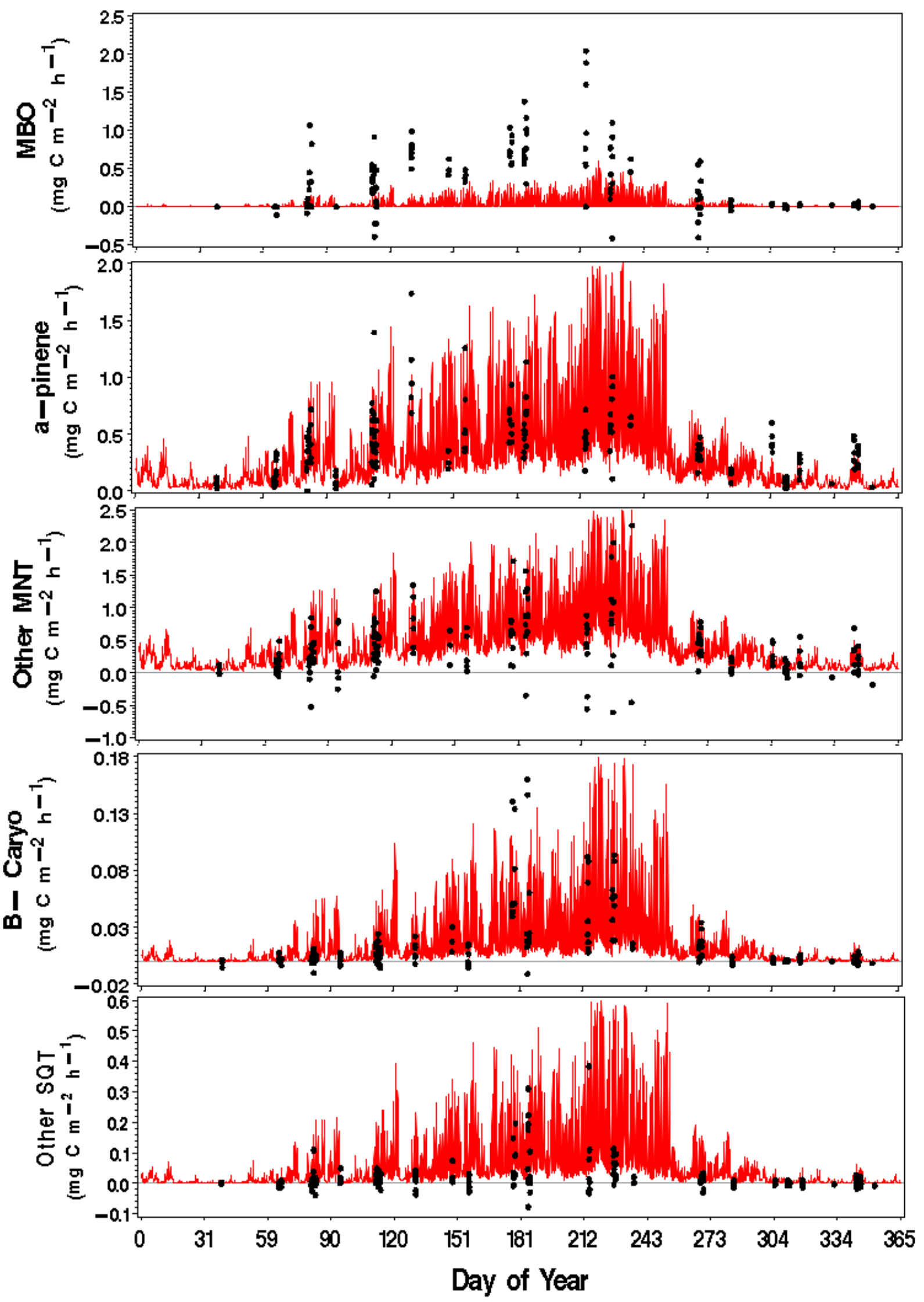



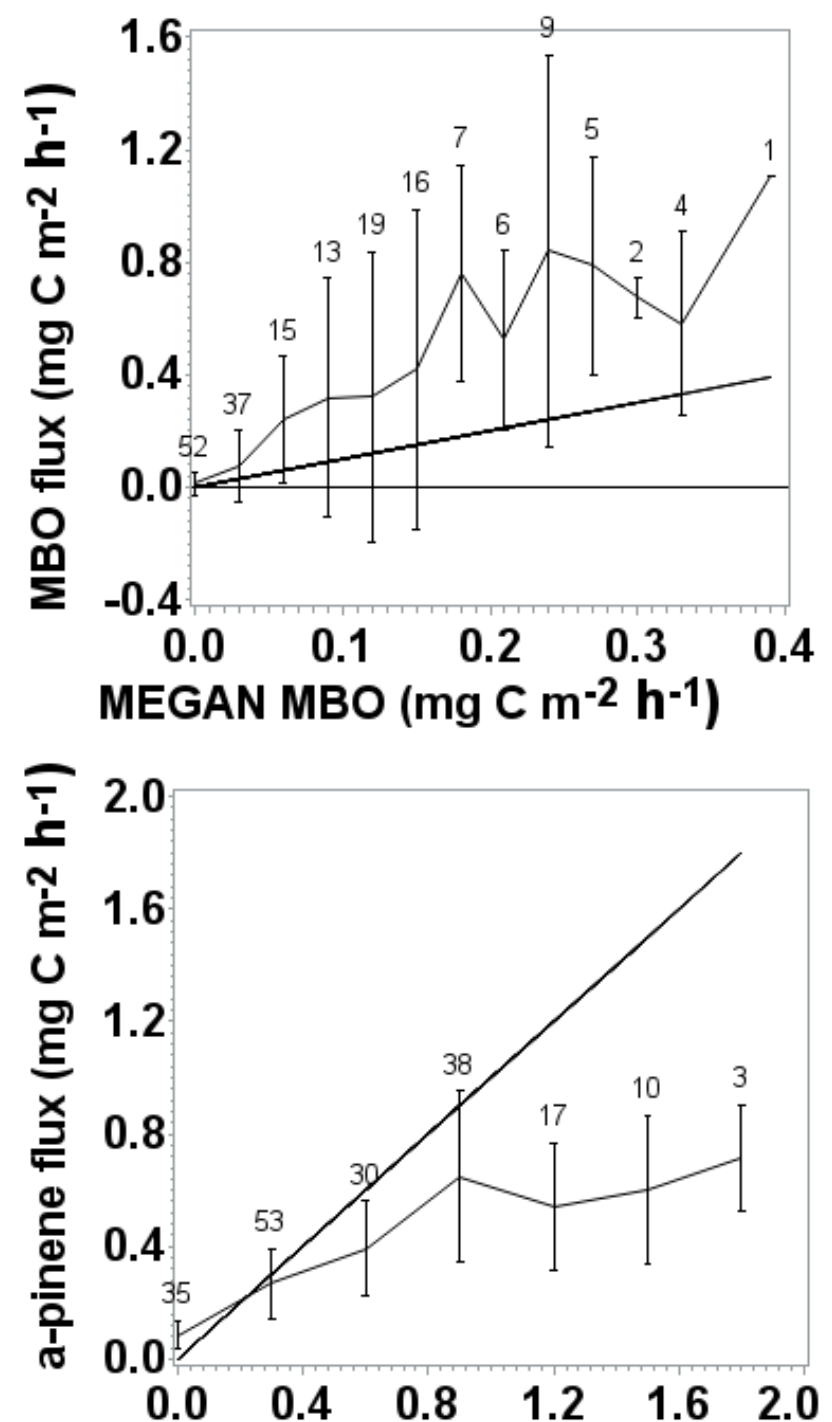

MEGAN a-pinene $\left(\mathrm{mg} \mathrm{C}^{-2} \mathrm{~h}^{-1}\right)$

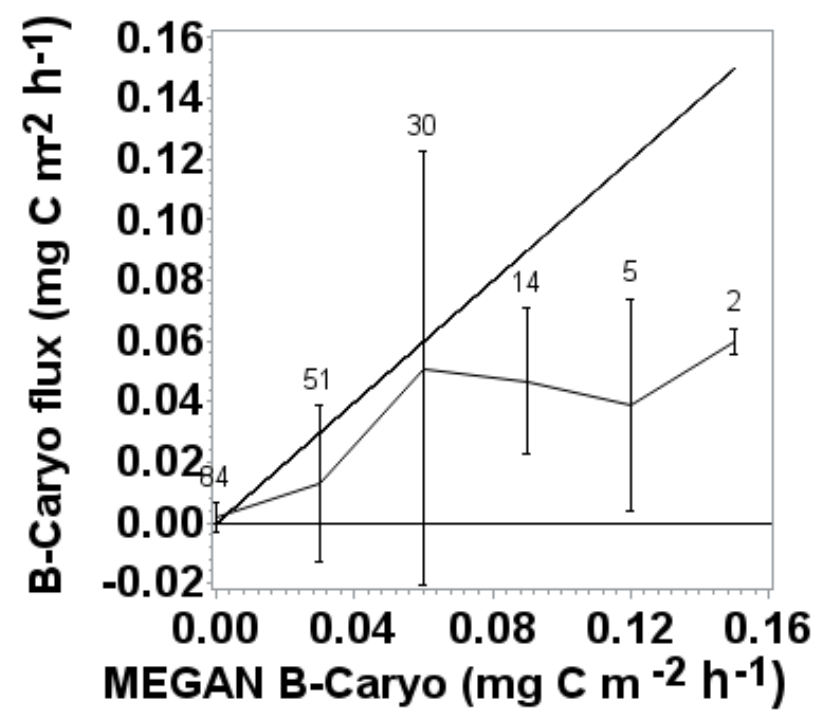

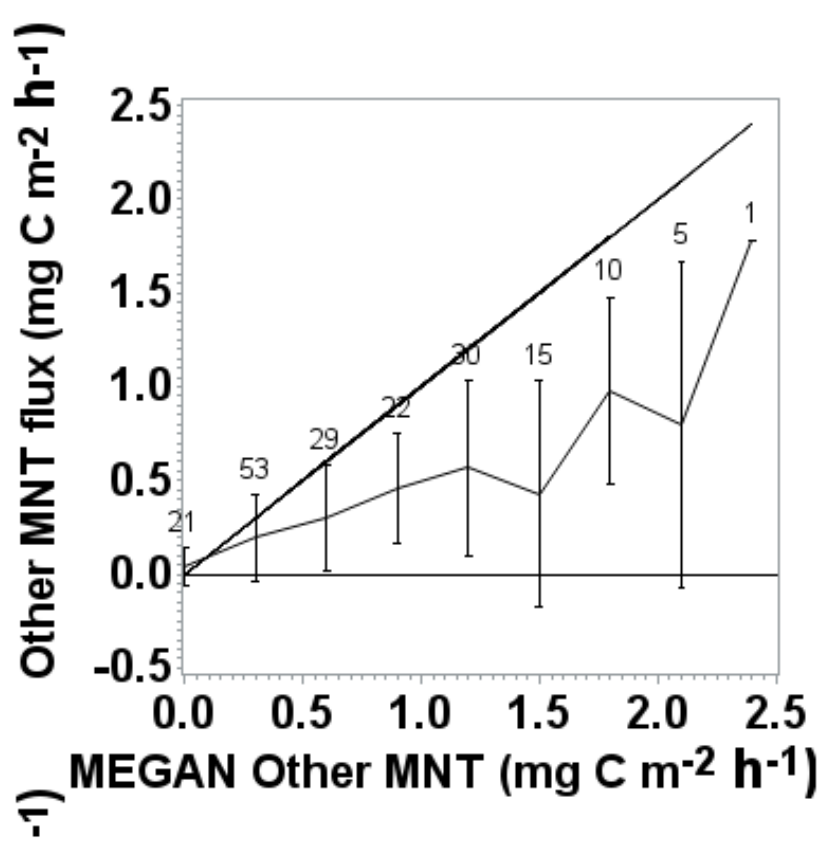

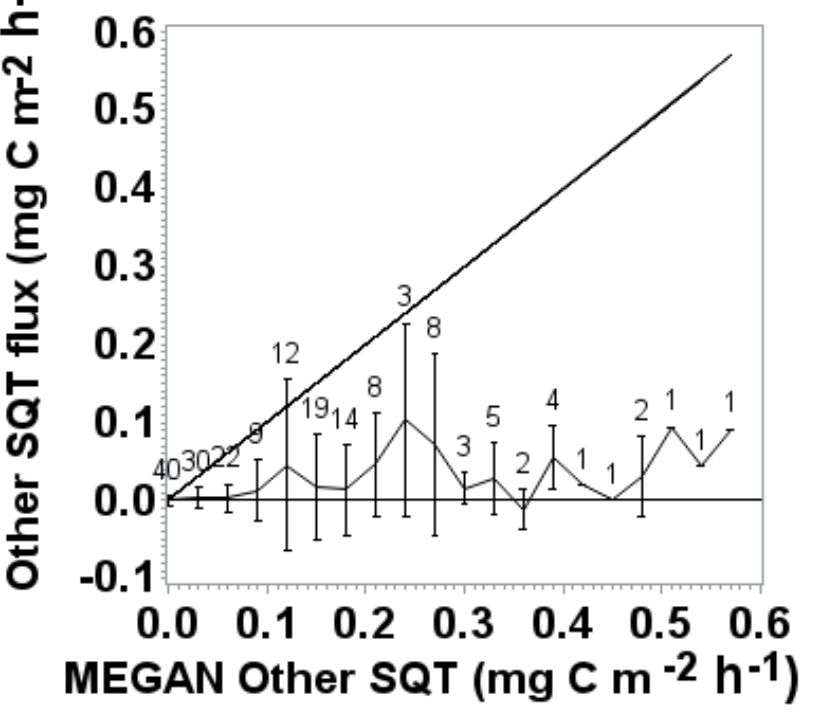

Figure 3. REA flux estimates in $\mathrm{mg} \mathrm{C} \mathrm{m}{ }^{-2} \mathrm{~h}^{-1}$ for $\alpha$-pinene, sum of other monoterpenes, $\beta$ caryophyllene, sum of other sesquiterpenes, and MBO (lines with error bars) compared with corresponding MEGAN bin mean outputs. Error bars denote 1 standard deviation about the mean 
REA flux for each MEGAN output interval. Diagonal straight lines represent 1:1 (perfect prediction). Numbers over the error bars indicate the number of flux measurements in each MEGAN output interval.

\subsection{MBO (2-methyl-3-buten-2-ol)}

Fluxes of MBO were roughly equal to $\alpha$-pinene fluxes averaged over the growing season and were over a factor of three greater than MEGAN MBO estimates (Figures 2 and 3). The MBO: $\alpha-$ pinene ratio declined by $70 \%$ in the dormant season. The temperature dependence of MBO was somewhat higher in the flux data compared to MEGAN.

The temperature dependence of $\mathrm{MBO}$, monoterpenes, and sesquiterpenes is calculated as

$$
M=M_{S} \cdot \mathrm{e}^{[\beta(T-T)]}
$$

where $M$ is $\mathrm{MBO}$, monoterpene, or sesquiterpene emission rate $\left(\mathrm{mg} \mathrm{C} \mathrm{m}^{-2} \mathrm{~h}^{-1}\right)$ at temperature $T$ $\left({ }^{\circ} \mathrm{C}\right), M_{S}$ is emission rate at standard $T_{S}\left(=30^{\circ} \mathrm{C}\right)$, e is the base of the natural logarithms, and $\beta$ is the temperature response factor and represents the proportional increase in emission rate per ${ }^{\circ} \mathrm{C}$ increase in temperature.

The MBO $\beta$ factor derived from the flux data was 0.17 (17\%) vs. 0.13 applied in MEGAN. However, for the growing season data, the MBO $\beta$ factor was 0.10 (see Figure 5). Analysis of the MBO flux on temperature regression residuals found no relationship between model residuals and photosynthetic photon flux density (PPFD), probably due to the high covariance between PPFD and upper canopy temperature in the flux dataset. This likely affects the $\beta$ factor comparisons discussed above as well. Harley et al. (1998) found that leaf MBO emissions were controlled by PPFD and leaf temperature and could be modeled using the same algorithms applied to isoprene emission.

Concentrations of MBO in REA updraft samples over the Pinus taeda plantation ranged from below detection limits in the winter to $1.4 \mathrm{ppbv}$ on sunny summer afternoons with ambient temperatures of $30-34^{\circ} \mathrm{C}$. From this tower on July 24, 2003, Stroud et al., (2005) observed midday (10 AM to $2 \mathrm{PM}$ ) above-canopy isoprene mixing ratios of 1.2-1.6 ppbv. Their total within-canopy vertical profile isoprene mixing ratios ranged from 1.5-2.1 ppbv, and isoprene oxidation products (methyl vinyl ketone + methacroleine) ranged from 2.0-1.7 ppbv. However, the PTR-MS used in that study could not distinguish MBO from isoprene (Karl et al. 2012). Based on our above canopy isoprene and MBO observations, we suspect that a significant fraction of the isoprene reported by Stroud et al. (2005) may have actually been MBO, although their vertical mixing ratio profiles (Figure 5 of Stroud et al., 2005) suggest that isoprene maxima correspond to leaf area profiles of Liquidambar styraciflua (a high isoprene emitter, but not known to emit MBO) as well as leaf area profiles of Pinus taeda. The corresponding abovecanopy isoprene flux from Stroud et al. (2005) was $550 \mu \mathrm{g} \mathrm{C} \mathrm{m}^{-2} \mathrm{~h}^{-1}$ (under sunny to partly cloudy skies and air temperatures of $26-30^{\circ} \mathrm{C}$ ) which compares to our late spring through summer MBO flux mean of $530 \mu \mathrm{g} \mathrm{C} \mathrm{m}^{-2} \mathrm{~h}^{-1}$.

The low levels of isoprene observed in our REA fluxes suggests that MBO conversion was less than $10 \%$ on warm sunny days, nonetheless, our reported MBO flux estimates may be biased somewhat low. The REA isoprene fluxes observed are less than $10 \%$ of MBO fluxes during the late spring and summer, and Liquidambar styraciflua within the tower footprint likely contributes to this isoprene flux (Stroud et al., 2005). 
The range in our MBO mixing ratios compares with peak updraft values of 0.6 ppbv observed by Baker et al. (2001) over a Pinus contorta canopy under sunny but cooler $\left(18^{\circ} \mathrm{C}\right)$ conditions. Schade and Goldstein (2001) measured peaks of 4-7 ppbv in updrafts over a Pinus ponderosa plantation during the summer at Blodgett Forest in California's Sierra Nevada Mountains. The MBO peaks at the latter site were associated with sunny (PPFD 1800-2000 $\mu \mathrm{mol} \mathrm{m} \mathrm{s}^{-2} \mathrm{~s}^{-1}$ ) and warm $\left(28-32^{\circ} \mathrm{C}\right)$ conditions. Kaser et al. (2013a) used a proton-transfer-reaction time-of-flight mass-spectrometer (PTR-TOF-MS) to measure BVOC fluxes over Pinus ponderosa in Colorado during an 11 day period in August of 2010. Additional ambient GC/MS data were used to confirm distinct MBO and isoprene fluxes, which can be confounded using the PTR-TOF-MS alone. They observed daytime peak MBO concentrations exceeding 2 ppbv during sunny (peak PPFD of $\left.\sim 2000 \mu \mathrm{mol} \mathrm{m}^{-2} \mathrm{~s}^{-1}\right)$ and warm $\left(27^{\circ} \mathrm{C}\right)$ daytime conditions. These data, summarized in Table 2, suggest similar source strengths despite large EF differences between Pinus species observed by Harley et al. (1998).

Table 2. Reported MBO fluxes from the current and previous studies.

\begin{tabular}{|c|c|c|c|c|c|}
\hline & \multicolumn{2}{|c|}{$\operatorname{MgCm^{-2}h^{-1}}$} & Max. & MBO Mixing ratio & $\%$ ground cover \\
\hline Study Year/State & MDM* & $\overline{\operatorname{Max}}$. & $\mathrm{Ta}^{*} / \mathrm{PPFD} *$ & Max, MDM (std. dev.) & Footprint MBO source \\
\hline${ }^{1}(7 / 1998) / \mathrm{CA}$ & 1.1 & 2.1 & $30 / 1900$ & not reported & $30 \%$ P. ponderosa $\left(185 \mathrm{~g} \mathrm{~m}^{-2}\right)$ \\
\hline $2(7 / 1998) / \mathrm{CA}$ & 3.0 & 3.1 & $32 / 2000$ & $19,2.6(1.4)$ & $30 \%$ P. ponderosa $\left(185 \mathrm{~g} \mathrm{~m}^{-2}\right)$ \\
\hline${ }^{3}(7-9 / 1999) / \mathrm{CA}$ & 1.5 & 3.0 & $32 / 1800$ & $7.0,1.9(0.5)$ & $30 \%$ P. ponderosa $\left(185 \mathrm{~g} \mathrm{~m}^{-2}\right)$ \\
\hline${ }^{4}(7-8 / 1999) / \mathrm{CO}$ & 0.9 & 1.0 & $18 / 1900$ & $0.7,0.6(0.02)$ & $43 \%$ Pinus contorta \\
\hline${ }^{5}(2007) / \mathrm{NC}$ & 0.9 & 2.0 & $36 / 1900$ & $3.5,1.0(0.4)$ & $80 \%$ Pinus taeda \\
\hline${ }^{6}(8-9 / 2010) / \mathrm{CO}$ & 1.5 & 2.9 & $27 / 2000$ & $3.0,2.1(0.5)$ & $38 \%$ P. ponderosa \\
\hline
\end{tabular}

*MDM - Mean Daily Maximum (summer fluxes).

*PPFD- Photosynthetic Photon Flux Density $\left(\mu \mathrm{mol} \mathrm{m} \mathrm{m}^{-2} \mathrm{~s}^{-1}\right)$

* Ta - air temperature above forest canopy $\left({ }^{\circ} \mathrm{C}\right)$

1 Baker et al. (1999).

2 Schade et al. (2000). Fluxes likely overestimated due to soil heating effects on diffusivity.

3 Schade and Goldstein (2001). Concentrations given for REA updrafts.

4 Baker et al. (2001). Concentrations given for REA updrafts.

5 Arnts et al. (2013). Concentrations given for REA updrafts.

6 Kaser et al. (2013a, b). Mixing ratios are approximations from 11-day August period.

Observed mean REA MBO fluxes were nearly a factor of four higher than MEGAN estimates on warm summer days (Figure 2). The discrepancy was decreased to less than a factor of three in the dormant season, when LAI (and therefore foliar biomass) was decreased by roughly $50 \%$ (Figure 1). Since MBO exhibits a light dependence similar to isoprene (Harley et al., 1998), model estimates of emissions are decreasingly sensitive to changes in LAI as LAI increases. For example, MEGAN midday summertime MBO emission values increase by approximately $7 \%$ if LAI increases from 5 to 6 , and decrease by approximately 13\% if LAI decreases from 5 to 3 . If LAI in MEGAN is set to 5 in the growing season and 3 during dormancy, the temporal ratio in MBO emissions (MEGAN/ REA flux) becomes more consistent, approaching 3.5 throughout the year. Accounting for seasonal changes in coniferous LAI may improve model estimates of BVOC emissions. Figure 2 shows the seasonal pattern in MEGAN outputs and REA fluxes. MBO fluxes often reached 1-2 $\mathrm{mg} \mathrm{C} \mathrm{m}^{-2} \mathrm{hr}^{-1}$, making MBO fluxes the largest of all BVOC emitted from this canopy on warm summer days, exceeding even $\alpha$-pinene. This observation contrasts with MEGAN, which yields estimates of $\alpha$-pinene emissions that are four times greater than MBO during warm summer days.

The MBO emission rates reported from the Duke Forest Pinus taeda plantation fall between those reported by Baker et al. (1999) and Schade et al. (2000). These investigators conducted 
flux measurements using REA and gradient methods, respectively, over Pinus ponderosa at Blodgett Forest in the Sierra Nevada Mountains of California. Summertime peak Pinus ponderosa biomass and projected LAI were $185 \mathrm{~g} \mathrm{~m}^{-2}$ and 2.1 , respectively. These values are probably somewhat low for the time periods of the flux studies, since flux measurements were made in 1998, while the biomass measurements were made in 1997, and the canopy was quite open (less than $35 \%$ canopy cover) during these periods. Mean summertime daily peak MBO fluxes were approximately 1.1 and $3.0 \mathrm{mg} \mathrm{m}^{-2} \mathrm{hr}^{-1}$ from Baker et al. (1999) and Schade et al. (2000), respectively, during conditions similar to the conditions during summer of 2007 at Duke Forest (maximum temperatures of 28-32 ${ }^{\circ} \mathrm{C}$, PPFD 1800-2000 $\mu \mathrm{mol} \mathrm{m} \mathrm{m}^{-2} \mathrm{~s}^{-1}$ ). Schade et al. (2000) acknowledged that their gradient technique probably overestimated $\mathrm{MBO}$ fluxes at Blodgett Forest due to soil surface heating effects on eddy diffusivity. The Baker et al. (1999) flux estimates were in agreement with model estimates based on local needle-level Pinus ponderosa MBO emission factors (Schade et al., 2000), which were $24 \%$ lower than the EFs measured by Harley et al. (1998).

During the following summer of 1999, Schade and Goldstein (2001) conducted their own REA measurements at Blodgett Forest. MBO fluxes were within the range of the previous two studies at this site. Mean daily peak MBO fluxes were approximately $1.5 \mathrm{mg} \mathrm{C} \mathrm{m}^{-2} \mathrm{hr}^{-1}$ at a mean temperature of $23{ }^{\circ} \mathrm{C}$ and reached as high as $2.3 \mathrm{mg} \mathrm{C} \mathrm{m}^{-2} \mathrm{hr}^{-1}$ when temperatures peaked at 32 ${ }^{\circ} \mathrm{C}$. Baker et al. (2001) reported peak daily $\mathrm{MBO}$ fluxes of $0.8-1.0 \mathrm{mg} \mathrm{C} \mathrm{m}^{-2} \mathrm{hr}^{-1}$ at air temperatures of $18^{\circ} \mathrm{C}$ and PPFD of $\sim 1500-1900 \mu \mathrm{mol} \mathrm{m}^{-2} \mathrm{~s}^{-1}$. Kaser et al. (2013a,b) performed eddy correlation measurements over a Pinus ponderosa forest near Manitou Springs, Colorado. Mean daily peak MBO fluxes were approximately $1.5 \mathrm{mg} \mathrm{C} \mathrm{m}^{-2} \mathrm{hr}^{-1}$ at a mean temperature of $23^{\circ} \mathrm{C}$, and reached as high as $2.9 \mathrm{mg} \mathrm{C} \mathrm{m}^{-2} \mathrm{hr}^{-1}$ when temperatures peaked at 27 ${ }^{\circ} \mathrm{C}$. Table 2 summarizes MBO fluxes and concentrations observed at the four sites. Kaser et al. (2013b) found that MEGAN underestimated MBO fluxes by a factor of 2-4 using default MEGAN emission factors, but agreement was very good (within 10\%) when applying emission factors determined from leaf cuvette measurements from Pinus ponderosa within the flux footprint at Manitou Forest. Our flux data suggest a similar adjustment to Pinus taeda MBO emission potential within MEGAN may be needed.

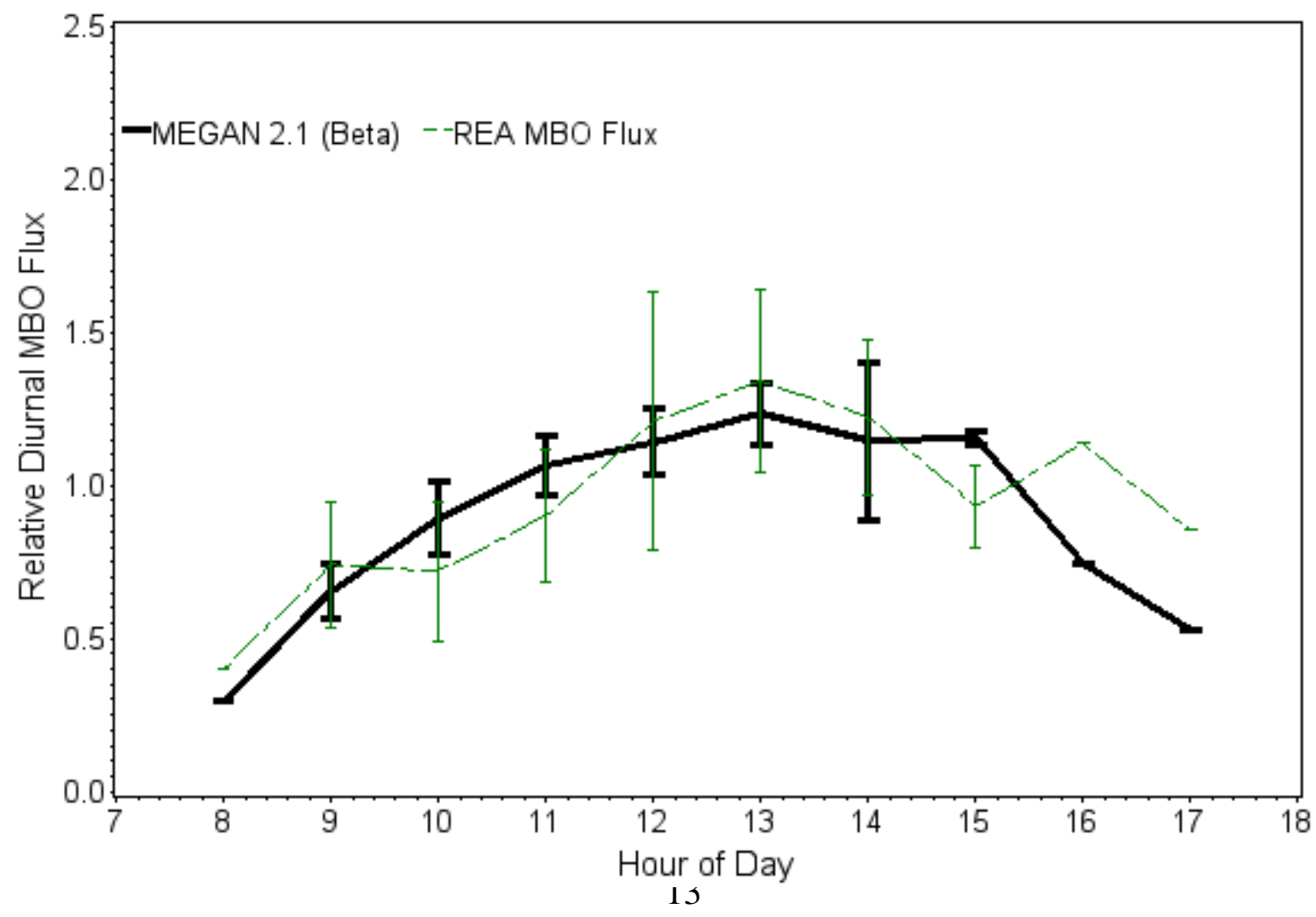


Figure 4. Daytime relative diurnal pattern in MEGAN outputs (solid black line) and REA fluxes (dashed green line) of MBO. Hourly REA and MEGAN values are expressed as a fraction of the respective daytime means for summer flux measurement days. Vertical bars denote \pm one standard deviation from the mean.

MEGAN simulates the diurnal pattern of MBO fluxes reasonably well. Figure 4 shows the mean summertime diurnal pattern of MEGAN outputs and REA fluxes. Both vary by a factor of 3-4 during daylight hours, although MEGAN estimates seem to decline more rapidly in the late afternoon than is suggested by the actual fluxes. This comparison is based on six total flux measurements for hours 16 and 17, however. Baker et al. (1999), Schade et al. (2000), and Schade and Goldstein (2001) report slightly more pronounced early afternoon peaks, although these studies also report noontime depression of MBO fluxes. Kaser et al. (2013a) also show midday depression of MBO concentrations above the Colorado Pinus ponderosa. However, a midday depression in the fluxes at this site is not reported by Kaser et al. (2013b). This noontime depression is also not apparent in the Pinus taeda flux data.

MEGAN allows the user to adjust the MBO emission potential as functions of previous solar radiation and temperature over 24 and 240 hours. These adjustments are empirical functions fitted to isoprene emission response and are likely not optimized for MBO. Nonetheless, adjusting the emission potential for the previous 24 hours PPFD and ambient above canopy temperature did improve MEGAN's correlation with REA MBO fluxes in the Pinus taeda plantation. In contrast, however, adjusting the EF as a function of the prior 240 hours degraded this correlation, as shown in Table 3 . The periodicity of meteorological change in the southeastern U.S. is typically more frequent than 240 hours, therefore, the longer term function may not add predictive power to the model. A similar short-term effect of previous solar radiation and temperature ( $<24$ hours) on leaf-level isoprene emission potential from Quercus alba was also observed at this site (Geron et al., 2000b).

Table 3. Pearson Correlation Coefficients between observed MBO fluxes and MEGAN2.1 MBO emission model estimates. MEGAN MBO emission estimates are adjusted for meteorology (temperature and PPFD, using isoprene adjustment algorithm) during the previous 24 and 240 hours (24/240), previous 240 hours only (240), previous 24 hours only (24), and unadjusted for prior meteorology (0/0). MEGAN correlations with REA fluxes are given for entire year and mid-spring through summer only (Days 100-273).

All Data $(\mathrm{N}=112)$

Prob $>|\mathrm{r}|$ under $\mathrm{H}_{0}: \mathrm{r}=0$

Days 100-273 (N=73)

Prob $>|\mathrm{r}|$ under $\mathrm{H}_{0}: \mathrm{r}=0$

\begin{tabular}{clll}
$24 / 240$ & 240 & 24 & $0 / 0$ \\
\hline 0.74 & 0.72 & 0.74 & 0.73 \\
$<.0001$ & $<.0001$ & $<.0001$ & $<.0001$ \\
& & & \\
0.48 & 0.41 & 0.50 & 0.45 \\
$<.0001$ & 0.0003 & $<.0001$ & $<.0001$
\end{tabular}

\subsection{Monoterpenes}

REA fluxes of $\alpha$-pinene and the sum of all other monoterpenes were approximately $50 \%$ lower than corresponding MEGAN estimates in the mid-spring through summer "growing season" (DOY 100-270). Figure 2 shows that MEGAN $\alpha$-pinene emission estimates are somewhat lower than REA fluxes early in the growing season, but higher than fluxes in August. Concentrations of $\alpha$-pinene in the up-drafts were highest in April and May, peaking at $3.8 \mu \mathrm{g} \mathrm{C} \mathrm{m}^{-3}$, or $0.75 \mathrm{ppbv}$. Our 2007 REA Fall, winter, and early spring "dormant season" (DOY < 100 and DOY > 270) $\alpha$ pinene emissions were within $20 \%$ of MEGAN estimates. However, MEGAN estimates of the sum of other monoterpenes exceeded REA fluxes by over a factor of two for this period. 
Previous BVOC flux studies over Pinus taeda canopies have primarily addressed $\alpha$-pinene and $\beta$-pinene. On July 24, 2003, Stroud et al., (2005) measured midday (10AM to 2 PM) total monoterpene (which are dominated by $\alpha$-pinene $+\beta$-pinene at this site) fluxes of $600 \mu \mathrm{g} \mathrm{C} \mathrm{m}^{-2} \mathrm{~h}^{-}$ ${ }^{1}$, from the same FACTS1 Ring6 tower. This is consistent with our midsummer estimates. Those authors observed within and above-canopy mixing ratios of monoterpenes ranging from $0.3-0.8$ ppbv. They used a vertically variable inlet and a proton transfer reaction mass spectrometer (PTR-MS) which could not distinguish between monoterpene isomers. Arnts et al. (1982) measured $\alpha$-pinene concentrations $1.7-3.3 \mathrm{ug} \mathrm{m}^{-3}(0.3-0.7 \mathrm{ppbv})$ and fluxes ranging from 580 to $1000 \mu \mathrm{g} \mathrm{C} \mathrm{m}^{-2} \mathrm{~h}^{-1}$ at $37{ }^{\circ} \mathrm{C}$ in late July and early August, 1980 over a Pinus taeda plantation on the coastal plain (Hertford County) of northeastern North Carolina. They used tracer release and atmospheric diffusion model methods, and their $\alpha$-pinene fluxes agree reasonably well with our REA estimates given the warmer ambient temperatures observed during the measurements of Arnts et al., (1982). Arnts et al. (1978) used a Bowen ratio technique to derive $\alpha$-pinene fluxes from a Pinus taeda canopy in the central Piedmont (Alamance County) of NC in mid to late July of 1977. Observed values ranged from 480 to $6300 \mu \mathrm{g} \mathrm{C} \mathrm{m}^{-2} \mathrm{~h}^{-1}$ over an ambient temperature range of 14 to $35^{\circ} \mathrm{C}$. These $\alpha$-pinene fluxes values range from equivalent to six times higher than the default MEGAN estimates. These authors note that the highest values were associated with onset of drought in August, which may increase leaf temperatures due to reduced transpiration, resulting in increased terpene flux (Wu et al., 2015). Of these four studies, July

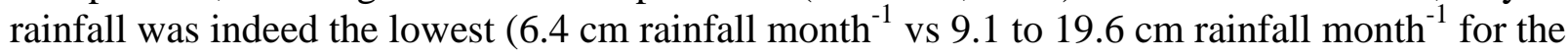
other three studies). Overall, the current study, Arnts et al., (1982), and Stroud et al., (2005) yielded summertime $\alpha$-pinene emission estimates ranging from 0.5 to 1 times MEGAN values, while Arnts et al., 1978 reports rates of 1 to 6 times MEGAN values.

\subsection{Sesquiterpenes}

Growing season MEGAN $\beta$-caryophyllene emission estimates were in reasonable agreement with REA data, exceeding REA fluxes by approximately 60\% (Table 1). However, the sum of other sesquiterpenes were a factor of four greater from MEGAN compared to the REA fluxes. MEGAN estimates $\alpha$-farnesene emission to be $80 \%$ of $\beta$-caryophyllene emission from Pinus taeda. Geron and Arnts (2010) found that branch enclosure emissions of total farnesene isomers were approximately $80 \%$ and $20 \%$ of $\beta$-caryophyllene emissions from Pinus taeda and $P$. virginiana respectively. Farnesene emissions were dominated by the trans- $\beta$ isomer from both tree species. Helmig et al. (2006) found that $\beta$-farnesene emissions were approximately $20 \%$ of $\beta$-caryophyllene emissions from branch enclosures of Pinus taeda at this site, and they concluded that light dependent emissions of sesquiterpenes could not be ruled out. $\beta$-farnesene and $\alpha$ bergamotene fluxes were found to be light and temperature dependent over a Pinus ponderosa plantation, while $\alpha$-farnesene fluxes were suspected to be dependent upon temperature only (Bouvier-Brown et al., 2009). Here, however, REA fluxes of $\alpha$-farnesene were only detected in 25 samples, were not statistically different from zero, and were negative (deposition) $64 \%$ of the time, while $\beta$-farnesene fluxes were not detected. Daly and Geron (manuscript in preparation) found no farnesenes in Pinus taeda needle extracts from this site, suggesting that these SQT compounds do not accumulate in glands or storage structures as do $\beta$-caryophyllene and $\alpha$ humulene. Gleizes et al. (1980) found that $\beta$-caryophyllene and $\alpha$-humulene could be synthesized in dark or illumination from the photosynthetic metabolite geranyl pyrophosphate and can be stored in resin ducts or glands. Conversely, the farnesenes are known to be produced from the precursor farnesyl pyrophosphate by farnesene synthase activity and emitted de novo, often in response to disturbance such as insect attack (Scutareanu et al., 1996). Farnesene de novo synthesis induced by thermal or contact disturbance could possibly explain farnesene emission within branch enclosures, while farnesene is apparently absent in the needle extract and REA flux samples. Kim at al. (2011) found that farnesene loss rates due to $\mathrm{OH}$ and $\mathrm{O}_{3}$ are on the order 
of an hour under typical rural oxidant conditions, while lifetimes for $\beta$-caryophyllene and $\alpha$ humulene are estimated to be as short as a few minutes (Shu and Atkinson, 1995). This suggests that rapid reactions with oxidants probably has a greater effect on $\beta$-caryophyllene and $\alpha$ humulene compared to the farnesenes. It is possible that the small, infrequent (and largely deposition) measurements of $\alpha$-farnesene flux were due to insect attack or other disturbance remote from the tower. The effects of enclosure disturbance, herbivory, atmospheric reactions, and above canopy fluxes of the farnesenes remain very uncertain.

\subsection{Composition of Emission, Model, and Extract Estimates}

Table 4 shows relative amounts of monoterpenes, oxygenated monoterpenes, and sesquiterpenes, measured with the REA, Pinus taeda branch enclosure estimates from Geron and Arnts (2010, G10), Helmig et al. (2006, H06), Ortega et al. (2008, O08) MEGAN emission estimates, and proportions from needle oil extracts (Daly and Geron, in preparation). There appears to be reasonable agreement in $\alpha$-pinene composition between the REA data, enclosure data, MEGAN, and the review of Geron et al. (2000). Percentages ranged from 38-58\%, while extracts were composed of $80 \% \alpha$-pinene. Conversely, extract concentrations of $\beta$-pinene were lower (11$12 \%)$ than the emissions (16-28\%) and MEGAN (25-27\%), indicating that the emissions and MEGAN were again in reasonable agreement (16-28\%) for $\beta$-pinene emissions. The extract data also indicated no limonene component, while MEGAN and REA compared well for limonene $(\sim 6-11 \%)$. The enclosure indicated a lower limonene contribution $(<3 \%) . \Delta 3$-carene was negligible in the emission and extract sources, but is $7-8 \%$ in MEGAN. Given that it is only $1 \%$ of Pinus taeda terpene composition in Geron et al. (2000), a reduction in this compound may be warranted in MEGAN. Harley et al. (2014) also suggested that a significant non-needle source of $\Delta 3$-carene is needed to balance ambient concentrations with its absence in branch enclosure emission measurements from Pinus ponderosa. Interestingly, the REA, enclosure (G10 and O08), and extract data indicate a 4-10\% $\beta$-phellandrene component, while H06, MEGAN and Geron et al. (2000) each indicate no significant $\beta$-phellandrene contribution. This compound may co-elute with limonene, which could possibly affect comparisons of these two compounds between the studies listed in Table 4.

Table 4. Percentage of each compound class (monoterpenes, oxygenated terpenes, and sesquiterpenes) accounted for by individual compounds from the Pinus taeda REA flux data, branch enclosure data: G10gs and G10oth (Geron and Arnts 2010, growing season and other, respectively), H06 (Helmig et al., 2006), and O08 (Ortega et al., 2008), MEGAN, needle extracts, and the monoterpene review (G2000) by Geron et al. (2000a). "GS" and "Other" indicate growing season and other season percentages, respectively. ' 'co-eluted with undecanal and is possibly significant (1-20\%) in enclosure OMT emissions, ${ }^{2}$ composed of $90 \%$ cis- $\alpha$-bergamotene and $10 \%$ trans- $\alpha$-bergamotene. Dashes (-) represent compounds not targeted in a given study.

\begin{tabular}{|c|c|c|c|c|c|c|c|c|c|c|c|}
\hline \multirow[b]{2}{*}{ Monoterpenes } & \multicolumn{2}{|l|}{ REA } & \multicolumn{4}{|c|}{ Branch Enclosure } & \multicolumn{2}{|c|}{ MEGAN2.1 } & \multicolumn{3}{|c|}{ Extract } \\
\hline & GS & Other & G10GS & G10C & $1 \mathrm{H06}$ & Ort08 & $\underline{\mathbf{G S}}$ & Other & $\underline{\text { GS }}$ & Other & $\underline{\mathrm{G} 2000}$ \\
\hline Tricyclene & 0.9 & 1.0 & 0.3 & 0.5 & - & - & - & - & 0.4 & 0.4 & - \\
\hline$\alpha$-thujene & 0 & 2.4 & & - & - & - & - & - & - & - & 0 \\
\hline$\alpha$-pinene & 52 & 57 & 47 & 49 & 57 & 38 & 44 & 42 & 80 & 79 & 58 \\
\hline$\alpha$-fenchene & 0.8 & 0.8 & & - & - & - & - & - & - & - & - \\
\hline camphene & 3.6 & 3.4 & 1.3 & 1.6 & - & - & - & - & 1.0 & 1.1 & 0.8 \\
\hline$\Delta 3$-carene & - & - & & - & - & - & 7.6 & 8.1 & - & - & 1.0 \\
\hline sabinene & 1.8 & 0.3 & 0.4 & - & - & 0.3 & 1.3 & 1.2 & - & - & 0 \\
\hline myrcene & 6.8 & 5.0 & 12 & 13 & 13 & 30 & 4.2 & 4.0 & 2.1 & 2.3 & 8.4 \\
\hline$\beta$-pinene & 17 & 16 & 28 & 21 & 26 & 19 & 25 & 27 & 11 & 12 & 24 \\
\hline$\alpha$-phellandrene & 0.6 & 0.6 & 0.7 & 1.0 & - & - & - & - & - & - & - \\
\hline$\alpha$-terpinene & 0.1 & 0 & 0.6 & - & - & - & - & - & - & - & 0.2 \\
\hline$\rho$-cymene & 1.0 & 1.5 & 0.4 & 0.7 & - & - & - & - & 0.5 & - & - \\
\hline d-limonene & 9.1 & 5.9 & 2.6 & 2.7 & 3 & - & 10 & 11 & - & - & 6.9 \\
\hline$\beta$-phellandrene & 4.3 & 5.9 & 6.3 & 9.0 & - & 10 & - & - & 4.3 & 4.7 & 0 \\
\hline
\end{tabular}




\begin{tabular}{|c|c|c|c|c|c|c|c|c|c|c|c|}
\hline$\gamma$-terpinene & 1.8 & 0.5 & 0.6 & 0.4 & - & - & - & - & 0 & - & - \\
\hline ocimene & - & - & & - & - & - & 2.4 & 2.0 & - & - & 0 \\
\hline terpinolene & - & - & 0.3 & 0.4 & - & - & - & - & 0.1 & 0.1 & 0 \\
\hline Other MNT & - & - & - & - & - & - & 5.5 & 5.6 & 0.7 & 1.2 & - \\
\hline \multicolumn{2}{|c|}{ Oxygenated Monoterpenes GS } & Other & G10GS & G100th & $1 \mathrm{H06}$ & Ort08 & GS & Other & GS & Other & G2000 \\
\hline cineole & - & - & 1.7 & 3.2 & - & - & 5.9 & 5.9 & - & - & - \\
\hline linalool & 39 & 64 & 62 & 30 & - & 95 & 32 & 32 & 2.1 & 5.2 & - \\
\hline linalool oxide & 2.1 & 11 & - & - & - & - & 9.0 & 9.0 & - & - & - \\
\hline$\beta$-terpineol & - & - & 5.3 & 19 & - & - & 1.6 & 1.6 & - & - & - \\
\hline nopinone & 12 & 18 & 11 & 13 & - & - & - & - & - & - & - \\
\hline camphor & 16 & 29 & 5.3 & 10 & - & - & 17 & 17 & - & - & - \\
\hline borneol & 2.8 & -4.7 & 1.7 & 3.0 & - & - & 2.1 & 2.1 & - & - & - \\
\hline terpin-4-ol & 5.8 & 4.4 & 3.0 & 4.0 & - & - & 1.6 & 1.6 & - & - & - \\
\hline$\alpha$-terpineol & 4.1 & -6.0 & 4.1 & 3.6 & - & - & 9.0 & 9.0 & - & - & - \\
\hline myrtenal & 3.7 & -8.3 & 2.5 & 4.6 & - & - & 1.6 & 1.6 & - & - & - \\
\hline verbenone & 4.4 & 8.0 & 2.8 & 8.8 & - & - & - & - & - & - & - \\
\hline linalool acetate & - & - & - & - & - & - & - & - & 75 & 85 & - \\
\hline bornyl acetate & $3.4^{1}$ & -12 & 2.0 & 5.1 & - & - & 1.6 & 1.6 & 22 & 10 & - \\
\hline Other OMT & 6.7 & 6.6 & 0.6 & 1.0 & - & 5 & 17 & 17 & - & - & - \\
\hline Sesquiterpenes & GS & Other & G10GS & G100th & $1 \mathrm{H06}$ & Ort08 & GS & Other & GS & Other & G2000 \\
\hline$\alpha$-cubebene & 0.2 & 1.2 & 0.5 & 1.1 & - & 1 & - & - & - & - & - \\
\hline$\alpha$-copaene & 5.4 & -8.6 & 0.5 & 1.5 & - & - & - & - & - & - & - \\
\hline$\beta$-elemene & 0.9 & 0.4 & 1.3 & 1.7 & - & 1 & - & - & - & - & - \\
\hline$\alpha$-bergamotene & $21^{2}$ & $36^{2}$ & 5.5 & 5.0 & 12 & 3 & - & - & - & - & - \\
\hline$\beta$-farnesene & - & - & 19 & 10 & 11 & - & - & - & - & - & - \\
\hline$\beta$-caryophyllene & 51 & 38 & 31 & 36 & 66 & 47 & 21 & 21 & 46 & 34 & - \\
\hline$\alpha$-humulene & 7.2 & 4.5 & 8.4 & 5.5 & 10 & 22 & - & - & 4.4 & 5.9 & - \\
\hline$\alpha$-farnesene & -0.2 & -0.8 & 4.8 & 10 & - & - & 17 & 17 & - & - & - \\
\hline$\gamma$-muurolene & - & -1.9 & 2.8 & 3.3 & - & 2 & - & - & - & - & - \\
\hline germacrene-D & - & - & - & - & - & 2 & - & - & 19 & 14 & - \\
\hline bicyclogermacrene & - & - & - & - & - & - & - & - & 22 & 31 & - \\
\hline germacrene-A & - & - & - & - & - & - & - & - & 1.9 & 2.9 & - \\
\hline$\alpha$-muurolene & 3.7 & 16 & 3.2 & 4.1 & - & 5 & - & - & - & - & - \\
\hline ledene & - & 1.9 & 0.8 & - & - & - & - & - & - & - & - \\
\hline$\beta$-gurjunene & - & - & 2.4 & 1.9 & - & 1 & - & - & - & - & - \\
\hline$\alpha$-cedrene & - & - & 9.3 & 9.5 & - & 1 & - & - & - & - & - \\
\hline$\beta$-cedrene & 3.3 & 11 & - & - & - & - & - & - & - & - & - \\
\hline nerolidol & 1.3 & -1.0 & 4.5 & 0.3 & - & - & - & - & - & - & - \\
\hline$\gamma$-cadinene & - & - & - & - & - & 4 & - & - & 3.9 & 6.6 & - \\
\hline$\delta$-cadinene & 4.9 & 6.9 & 4.3 & 7.2 & - & 8 & - & - & 3.2 & 5.5 & - \\
\hline$\alpha$-cadinene & - & - & 1.4 & 2.0 & - & - & - & - & - & - & - \\
\hline Other SQT & 1.3 & 0 & - & - & - & 4 & 62 & 62 & 0 & 0.1 & - \\
\hline
\end{tabular}

The oxygenated terpenes in MEGAN output from Pinus taeda plantations are aggregated into the "other monoterpene" category, where they make up a few percent of total terpenes. Linalool and camphor are the primary oxygenated monoterpene compounds within MEGAN. The emission of these oxygenates typically is small compared to the hydrocarbon terpenes, composing 1-10\% percent of total terpenes in the REA data as well as in the G10 and O08 branch enclosure data. Linalool (the dominant compound), nopinone, and camphor are among the more significant oxygenated terpene species emitted, although these can also be oxidation products of myrcene, the pinenes, and other terpenes. Small deposition fluxes of some of these compounds are also indicated in Table 4. Extract percentages of linalool are small compared to emissions, indicating that linalool may be a de novo light dependent emission or an atmospheric oxidation product. It is also possible that the low extract percentage of linalool is partly due to abundance of linalool acetate, which has a $\sim 50 \%$ lower vapor pressure (and a $20^{\circ} \mathrm{C}$ melting point) than linalool and would likely be lost to emission at lower rates. Harley et al. (2014) found that oxygenated monoterpenes, dominated by linalool, accounted for up to $75 \%$ of monoterpenoid emissions from 
Pinus ponderosa. Oxygenated monoterpene emission will likely be enhanced in future versions of MEGAN and warrants future research efforts.

Sesquiterpene estimates from MEGAN for Pinus taeda are currently composed of $21 \% \beta$ caryophyllene, $17 \% \alpha$-farnesene, and $62 \%$ "other sesquiterpenes". Emissions of $\alpha$-humulene are often $5-40 \%$ of $\beta$-caryophyllene from many pines, and that is the case in the REA, enclosure, and extract data shown in Table 4. $\beta$-caryophyllene is lower as a percentage of total sesquiterpenes in MEGAN compared to the extract, REA, and enclosure emissions data. As discussed above, farnesene emission could be impacted by physical disturbance, which could explain the differences between REA and enclosure measurements. No farnesenes were detected in the needle extract data, suggesting that the farnesenes could indeed be produced and emitted rapidly and not stored as discussed above. $\alpha$-bergamotene emissions were also significant in the REA and branch enclosure data, but were not detected in the extracts, nor are they an explicit emission within MEGAN. Bicyclogermacrene, germacrene-D, and germacrene-A together account for over $40 \%$ of the extract sesquiterpene mass, but are not detected in the emissions. Germacrene-D has a vapor pressure about half that of $\beta$-caryophyllene, which suggest that volatility may induce lower emissions of germacrene-D relative to $\beta$-caryophyllene. However, $\beta$-caryophyllene and bicyclogermacrene vapor pressures are very similar $\left(1.733 \mathrm{~Pa} @ 25.0^{\circ} \mathrm{C}\right.$, www.chemspider.com/Chemical-Structure.4444848.html). It is also possible that the germacrene compounds are stored in peltate glandular trichomes or other structures that require wounding or rupture to release the sesquiterpene as opposed to hairy trichomes or resin ducts which offer less resistance to inter-cellular spaces and the atmosphere.

\subsection{Seasonal and Temperature Effects}

MEGAN appears to capture the timing of springtime monoterpene emission initiation (Figure 2). However, springtime sesquiterpene REA fluxes lag behind the springtime estimates from MEGAN. As a result, MEGAN estimates of $\beta$-caryophyllene and the sum of other sesquiterpenes were 7 and 25 times higher than corresponding REA fluxes in the dormant season (Table 1). The seasonal leaf area dynamics discussed above, as well as seasonal variations in leaf oil content, composition and capacity for de novo synthesis, are likely contributing factors to these seasonal differences. This is supported by the seasonal patterns in enclosure sesquiterpene emissions (Geron and Arnts, 2010) and the extract data. CEE values for many of the compounds within MEGAN are also highly uncertain and are dependent upon varying levels of oxidant mixing ratios within and above the canopy.

The temperature dependence of $\alpha$-pinene was somewhat lower $(\beta=0.06)$ in the flux data compared to MEGAN $(\beta=0.10)$, which at least partially accounts for the better agreement between REA and MEGAN $\alpha$-pinene emissions in the dormant season compared to the growing season. The mean $\beta$-caryophyllene $\beta$ factor derived from the flux data $(0.155)$ is similar to the value (0.17) assumed in MEGAN. These $\beta$ factors were calculated from the flux data for the entire year. Figure 5 illustrates this temperature dependence of BVOC emissions for the growing season and dormant periods. The natural logarithm of REA flux versus upper canopy air temperature $\left({ }^{\circ} \mathrm{C}\right)$ for $\mathrm{MBO}, \alpha$-pinene, the sum of other monoterpenes, $\beta$-caryophyllene, and the sum of other sesquiterpenes is calculated separately for the growing and dormant seasons. The $\beta$ factors are similar to or somewhat lower than MEGAN values, although the variability in this relationship for the sum of other monoterpenes and the sum of other sesquiterpenes is high, resulting in unstable estimates. The levels (or intercepts) of the regressions shown in Figure 5 also indicate significant seasonal effects independent of temperature effects for MBO and sesquiterpenes, suggesting that "basal emission" factors are significantly higher in the growing 
season for these compounds. Temperature appears to explain most of the variability between the two periods for monoterpene REA fluxes.
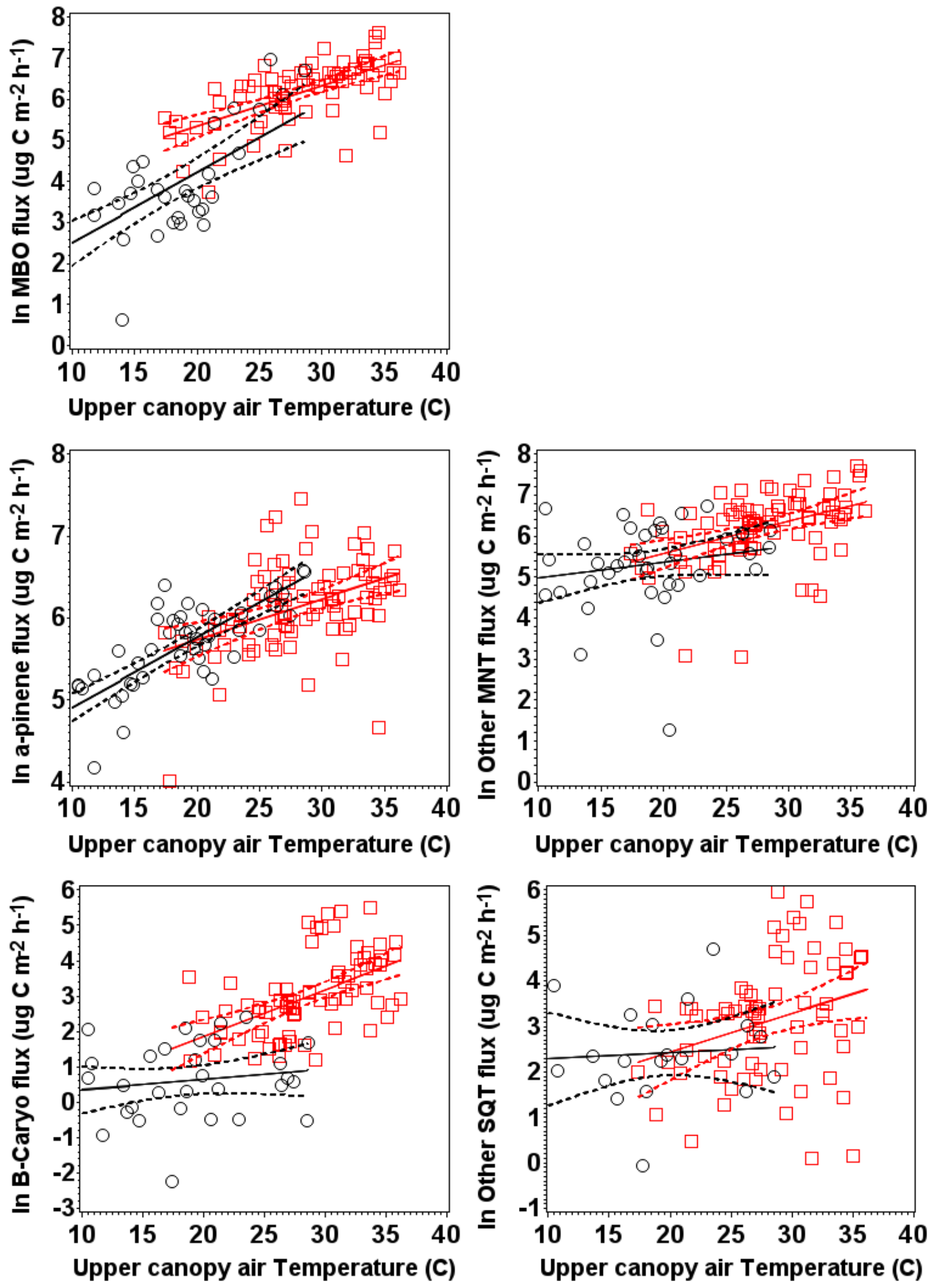
Figure 5. Natural logarithm of REA flux versus upper canopy air temperature $\left({ }^{\circ} \mathrm{C}\right)$ for $\mathrm{MBO}, \alpha$ pinene, the sum of other monoterpenes, $\beta$-caryophyllene, and the sum of other sesquiterpenes. The red squares represent REA fluxes during mid-spring through summer (DOY 100-270), and the red line represents the least squares regression fit to these data. The black circles represent REA fluxes during fall, winter, and early spring (DOY < 100 and DOY > 270), and the black line represents the least squares regression fit to these data. Dashed lines denote $95 \%$ confidence limits. The $\beta$ factors, or fraction of change in flux per ${ }^{\circ} \mathrm{C}$ change in temperature (given as values for DOY < 100 and DOY > 270, DOY 100-270 \pm standard error of the mean) are $(0.17 \pm 0.027$, $0.100 \pm 0.014)$ for $\mathrm{MBO},(0.085 \pm 0.008,0.050 \pm 0.011)$ for $\alpha$-pinene, $(0.039 \pm 0.028,0.079 \pm$ $0.019)$ for the sum of other monoterpenes, $(0.030 \pm 0.031,0.133 \pm 0.025)$ for $\beta$-caryophyllene, and $(0.014 \pm 0.044,0.085 \pm 0.033)$ for the sum of other sesquiterpenes. The low fall, winter, and early spring $\beta$ factors are highly uncertain, especially for the sesquiterpenes, due to the low observed concentrations and increased variability in fluxes at low temperatures.

\subsection{Conclusions}

Based on our comparison with the Pinus taeda data, the mean MEGAN canopy level EF for MBO is approximately a factor of three lower than the EF derived from the REA fluxes. Growing season monoterpene EFs appear to be high by a factor of two in MEGAN, while dormant season $\alpha$-pinene factors appear to be in reasonable agreement, partly due to the lower $\beta$ (temperature response factor) observed in the seasonal $\alpha$-pinene flux data. The MEGAN $\beta$-caryophyllene $\mathrm{EF}$ is within $60 \%$ of that derived from the flux data during the growing season, which is encouraging given the very high reactivity and short lifetime of this compound. Other sesquiterpenes were several times higher in MEGAN compared to the REA flux data. This area of uncertainty in both model development as well as flux measurement technology remains important.

Relative emission potential (REP) discussed in Geron et al. (1994, 2000a) provides a means of ranking the importance of each tree species in the USDA FIA inventory as a BVOC emitter. REP is calculated as the product of the basal BVOC EF (for instance, total monoterpene in $\mu \mathrm{gC} \mathrm{g}$ (leaf dry weight $)^{-1} \mathrm{~h}^{-1}$ ), the estimated fraction of the total crown coverage within the US, and foliar density for each species. Based on data available in 2000, Pinus taeda accounted for almost $12 \%$ of total U.S. monoterpene emission potential. Despite the somewhat lower monoterpene emissions reported here, the actual percentage of monoterpene emissions from this species may be higher, since it is a southern pine exposed to higher temperatures and a longer growing season than most species in the U.S. If MBO and sesquiterpene emissions are higher from Pinus taeda than other southern pines, its importance as a regional BVOC source may be further enhanced. In addition, as genetically improved Pinus taeda seedlings with higher growth and LAI potential are planted on an expanding area, its potential importance could change significantly. Clearly, BVOC emissions from genetically modified Pinus taeda plantations are an important regional research focus for southeastern U.S. air quality modeling.

\subsection{Acknowledgments}

This research was supported by the Office of Science (BER), U.S. Department of Energy, Grant No. DE-FG02-95ER62083. Meteorological data were obtained under the U.S. Department of Energy Contract No. DE-AC02-98CH10886 with Brookhaven National Laboratory. The United States Environmental Protection Agency produced the research described here. It has been subjected to Agency's administrative review and approved for publication. 


\subsection{Citations}

Arnts, R.R., Seila, R.L., Kuntz, R.L., Mowry, F.L., Knoerr, K.R., Dudgeon, A.C. 1978. Measurements of $\alpha$-pinene fluxes from a loblolly pine forest. Amer Chem Soc. 4th Joint Conf. New Orleans, LA. pp 829-833.

Arnts, R.R., Peterson, W.B., Seila, R.L. Gay, B.W. Jr. 1982. Estimates of $\alpha$-pinene emissions from a loblolly pine forest using an atmospheric diffusion model. Atmospheric Environment 16(9): 2127-2137.

Arnts, R.R. 2008. Reduction of Biogenic VOC Sampling Losses from Ozone via trans-2-Butene Addition. Environmental Science \& Technology 42(20):7663-7669.

Arnts, R.R. 2010. Evaluation of adsorbent sampling tube materials and Tenax-TA for analysis of volatile biogenic organic compounds. Atmospheric Environment 44:1579-1584.

Arnts, R. R., F. L. Mowry, and G. A. Hampton. 2013. A high-frequency response relaxed eddy accumulation flux measurement system for sampling short-lived biogenic volatile organic compounds, J. Geophys. Res. Atmos., 118, 4860-4873, doi:10.1002/jgrd.50215.

Baker, B., Guenther, A., Greenberg, J., and Fall, R. 2001. Canopy level fluxes of 2-methyl-3buten-2-ol, acetone, and methanol by a portable relaxed eddy accumulation system. Environmental Science \& Technology, 35 (9): 1701-1708.

Baker, B., Guenther, A., Greenberg, J., Goldstein, A., and Fall, R. 1999. Canopy fluxes of 2methyl-3-buten-2-ol over a ponderosa pine forest by relaxed eddy accumulation: Field data and model comparison. Journal of Geophysical Research: Atmospheres, 104(D21):26107-26114.

Bouvier-Brown, N. C., Goldstein, A. H., Gilman, J. B. Kuster, W. C., and de Gouw, J. A. 2009. In-situ ambient quantification of monoterpenes, sesquiterpenes, and related oxygenated compounds during BEARPEX 2007: implications for gas- and particle-phase chemistry. Atmos. Chem. Phys. 9(15): 5505-5518.

Carlton, A. G., Wiedinmyer, C., Kroll, J. H. 2009. A review of secondary organic aerosol (SOA) formation from isoprene. Atmos. Chem. Phys. 9, 4987-5005, www.atmos-chemphys.net/9/4987/2009/.

Daly, R.W. and Geron, C.D. 2014. Seasonal variation in Pinus taeda monoterpene and sesquiterpene essential oil components. Manuscript in Preparation.

Fox, T.R., Allen, H.L., Albaugh, T.J., Rubilar, R., and Carlson, C.A. 2006. Forest Fertilization in Southern Pine Plantations. Better Crops 3:12-15.

Geron, C., 2009. Carbonaceous aerosol over a Pinus taeda forest in Central North Carolina, USA. Atmospheric Environment 43, 959-969.

Geron, C.D., and Arnts, R.R. 2010. Seasonal monoterpene and sesquiterpene emissions from Pinus taeda and Pinus virginiana. Atmospheric Environment 44(34):4240-4251. 
Geron, C., Rasmussen, R., Arnts, R.R., Guenther, A. 2000a. A review and synthesis of monoterpene speciation from forests in the United States. Atmospheric Environment 34(11):1761-1781.

Geron, C., Guenther, A., Sharkey, T.D., Arnts, R.R. 2000b. Temporal variability in the basal isoprene emission factor. Tree Physiology 20(12): 799-805.

Geron C., Guenther, A., Pierce, T. 1994. An improved model for estimating emissions of volatile organic compounds from forests in the eastern United States. Journal of Geophysical Research 99(D6):12,773-12,791.

Gleizes, M., Pauly, G., Bernard-Dagan, C., and Jacques, R. 1980. Effects of light on terpene hydrocarbon synthesis in Pinus pinaster. Physiol Plant. 50:16-20.

Guenther, A. 2013. Upscaling Biogenic Volatile Compound Emissions from Leaves to Landscapes. Biology, Controls and Models of Tree Volatile Organic Compound Emissions. Ü. Niinemets and R. K. Monson, Springer Netherlands. 5: 391-414.

Guenther, A. B., Jiang, X., Heald, C. L., Sakulyanontvittaya, T., Duhl, T., Emmons, L. K., and Wang, X. 2012. The Model of Emissions of Gases and Aerosols from Nature version 2.1 (MEGAN2.1): an extended and updated framework for modeling biogenic emissions. Geosci. Model Dev. Discuss. 5, 1503-1560, doi:10.5194/gmdd-5-1503-2012.

Guenther, A., Karl, T., Harley, P., Wiedinmyer, C., Palmer, P.I., Geron, C. 2006. Estimates of global terrestrial isoprene emissions using MEGAN (Model of Emissions of Gases and Aerosols from Nature). Atmospheric Chemistry and Physics 6:3181-3210.

Hanna, S. R., et al. 2005. "Monte Carlo estimation of uncertainties in BEIS3 emission outputs and their effects on uncertainties in chemical transport model predictions." Journal of Geophysical Research-Atmospheres 110(D01302).

Harley, P., Eller, A., Guenther, A., Monson, R.K. 2014. Observations and models of emissions of volatile terpenoid compounds from needles of ponderosa pine trees growing in situ: control by light, temperature and stomatal conductance. Oecologia 176: 35-55 DOI 10.1007/s00442-0143008-5

Harley P., Fridd-Stroud, V., Greenberg, J., Guenther, A., and Vasconcellos, P. 1998. Emission of 2-methyl-3-buten-2-ol by pines: A potentially large natural source of reactive carbon to the atmosphere. Journal of Geophysical Research 103:25479-25486.

Helmig, D., Ortega, J., Guenther, A., Herrick, J.D., Geron, C. 2006. Sesquiterpene emissions from loblolly pine and their potential contribution to biogenic aerosol formation in the Southeastern US. Atmospheric Environment 40(22): 4150-4157.

Jaoui, M., Kleindienst, T. E., Offenberg, J. H., Lewandowski, M., Lonneman, W. A. 2011. SOA formation from the atmospheric oxidation of 2-methyl-3-buten-2-ol and its implications for $\mathrm{PM}_{2.5}$. Atmos. Chem. Phys. Discuss., 11(8): 24043-24083, www.atmos-chem-physdiscuss.net/11/24043/2011/ doi:10.5194/acpd-11-24043-2011

Karl, T., Hansel, A., Cappellin, L., Kaser, L., Herdlinger, I., and Jud, W. 2012. Selective measurements of isoprene and 2-methyl-3-buten-2-ol based on NO+ ionization mass 
spectrometry, Atmos. Chem. Phys. Discuss., 12, 19349-19370, doi:10.5194/acpd-12-193492012.

Kaser, L., Karl, T., Schnitzhofer, R., Graus, M., Herdlinger-Blatt, I. S., DiGangi, J. P., Sive, B., Turnipseed, A., Hornbrook, R. S., Zheng, W., Flocke, F. M., Guenther, A., Keutsch, F. N., Apel, E., and Hansel, A. 2013a. Comparison of different real time VOC measurement techniques in a ponderosa pine forest, Atmos. Chem. Phys. 13, 2893-2906, doi:10.5194/acp-13-2893-2013.

Kaser, L., Karl, T, Guenther, A., Graus, M, Schnitzhofer, R., Turnipseed, A., Fischer, L., Harley, P, Madronich, M., Gochis, D, Keutsch, F. N., and Hansel, A. 2013b. Undisturbed and disturbed above canopy ponderosa pine emissions: PTR-TOF-MS measurements and MEGAN 2.1 model results, Atmos. Chem. Phys. Discuss. 13, 15333-15375.

Kim, D., Stevens, P.S., and Hites, R.A. 2011. Rate constants for the gas-phase reactions of OH and $\mathrm{O}_{3}$ with $\beta$-ocimene, $\beta$-myrcene, and $\alpha$ - and $\beta$-farnesene as a function of temperature. J Phys Chem A. 115(4):500-6. doi: 10.1021/jp111173s. Epub 2010 Dec 17.

Lamb, B., et al. 1987. A National Inventory of Biogenic Hydrocarbon Emissions. Atmospheric Environment 21(8): 1695-1705.

Lamb, B., et al. 1996. Evaluation of forest canopy models for estimating isoprene emissions. Journal of Geophysical Research-Atmospheres 101(D17): 22787-22797.

McKeand, S., Mullin, T., Byram, T., White, T. 2003. Deployment of Genetically Improved Loblolly and Slash Pines in the South. Journal of Forestry 101:32-37.

Misztal, P. K., et al. 2014. Airborne flux measurements of biogenic isoprene over California. Atmos. Chem. Phys. 14(19): 10631-10647.

Neale, D.B., and Wheeler, N.C. 2004. The Loblolly Pine Genome Project. 2004. http://dendrome.ucdavis.edu/NealeLab/lpgp/pdf/prospectus.pdf

Ortega, J., Helmig, D., Daly, R. W., Tanner, D. M., Guenther, A. B., Herrick, J. D. 2008. Approaches for quantifying reactive and low-volatility biogenic organic compound emissions by vegetation enclosure techniques - Part B: Applications. Chemosphere 72: 365-380. Doi: 10.1016/j.chemosphere.2008.02.054.

Prestemon, J.P. and Abt, R.C. 2008. Southern Forest Resource Assessment: Chapter 13 (TIMBR-1): Timber Products Supply and Demand. Southern Research Station, USDA Forest Service, Research Triangle Park, NC. 84 pages.

Schade, G.W., and Goldstein, A.H. 2001. Fluxes of oxygenated volatile organic compounds from a ponderosa pine plantation, Journal of Geophysical Research: Atmospheres 106(D3):31113123.

Schade, G.W., Goldstein, A.H., Gray, D.W., and Lerdau, M.T. 2000. Canopy and leaf level 2methyl-3-buten-2-ol fluxes from a ponderosa pine plantation, Atmospheric Environment 34(21):3535 - 3544 . 
Scutareanu, P., Drukker, B., Bruin, J., Posthumus, M. A., and Sabelis, M. W. 1996. Leaf volatiles and polyphenols in pear trees infested by Psylla pyricola. Evidence of simultaneously induced responses, Chemoecology 7(1):34-38.

Shu,Y., and Atkinson,R. 1995. Atmospheric lifetimes and fate of a series of sesquiterpenes, J of Geophys Res. 100(D4):7275-7281.

Steiner, A. L., Tonse, S., Cohen, R. C., Goldstein, A. H., and Harley, R. A. 2007. Biogenic 2methyl-3-buten-2-ol increases regional ozone and HOx sources, Geophys. Res. Lett., 34, L15806, doi:10.1029/2007GL030802.

Stroud, C., Makar, P., Karl, T., Guenther, A., Geron, C., Turnipseed, A., Nemitz, E., Baker, B., Potosnak, M., Fuentes, J. D. 2005. Role of canopy-scale photochemistry in modifying biogenicatmosphere exchange of reactive terpene species: Results from the CELTIC field study. Journal of Geophysical Research: Atmospheres 110(D17):D17303.

Trainer, M., Williams, E.J., Parrish, D.D., Buhr, M.P., Allwine, E.J., Westberg, H.H., Fehsenfeld, F.C., Liu, S.C. 1987. Models and observations of the impact of natural hydrocarbons on rural ozone. Nature 329:705-707

Vose, J.M. and Allen, H.L. 1988. Leaf area, stem wood growth, and nutrition relationships in loblolly pine. Forest Science 34(3):547-563.

Warneke, C., et al. 2010. Biogenic emission measurement and inventories determination of biogenic emissions in the eastern United States and Texas and comparison with biogenic emission inventories. Journal of Geophysical Research-Atmospheres 115.

Wu, C., Pullinen, I., Andres, S., Carriero, G., Fares, S., Goldbach, H., Hacker, L., Kasal, T., Kiendler-Scharr, A., Kleist, E., Paoletti, E., Wahner, A., Wildt, J., and Mentel, Th. F. 2015. Impacts of soil moisture on de novo monoterpene emissions from European beech, Holm oak, Scots pine, and Norway spruce, Biogeosciences, 12, 177-191, doi:10.5194/bg-12-177-2015. 
